NBER WORKING PAPER SERIES

\title{
HOSPITAL OWNERSHIP AND FINANCIAL PERFORMANCE: A QUANTITATIVE RESEARCH REVIEW
}

\author{
Yu-Chu Shen \\ Karen Eggleston \\ Joseph Lau \\ Christopher Schmid \\ Working Paper 11662 \\ http://www.nber.org/papers/w11662
}

\author{
NATIONAL BUREAU OF ECONOMIC RESEARCH \\ 1050 Massachusetts Avenue \\ Cambridge, MA 02138 \\ September 2005
}

The authors gratefully acknowledge funding for this research from grant \#050953 under the Robert Wood Johnson Foundation's Changes in Health Care Financing and Organization (HCFO) Initiative. We thank Jia Chan, Mantian Hu, Ania Aksan, and Pam Kum for excellent research assistance. We also thank Drs. Dena Bravata, Ingram Olkin, and our expert panel members for providing valuable inputs: Drs. Kathleen Carey, Shin-Yi Chou , Leemore Dafny, Guy David, Mark Duggan, Darrel Gaskin, Martin Gaynor, Michael McCue, Jack Needleman, Michael Rosko, Joanne Spetz, Robert Town, and Kevin Volpp. We are also grateful to participants at the Research-in-Progress Seminar at Stanford University, the 2005 Academy Health Annual Research Meeting, and the 2005 International Health Economics Association meeting for their helpful comments. The views expressed herein are those of the author(s) and do not necessarily reflect the views of the National Bureau of Economic Research.

(C2005 by Yu-Chu Shen, Karen Eggleston, Joseph Lau and Christopher Schmid. All rights reserved. Short sections of text, not to exceed two paragraphs, may be quoted without explicit permission provided that full credit, including (C) notice, is given to the source. 
Hospital Ownership and Financial Performance: A Quantitative Research Review

Yu-Chu Shen, Karen Eggleston, Joseph Lau and Christopher Schmid

NBER Working Paper No. 11662

September 2005, Revised June 2006

JEL No. I11, L30

\begin{abstract}
We apply meta-analytic methods to conduct a quantitative review of the empirical literature since 1990 comparing financial performance of US for-profit, not-for-profit, and government-owned general acute hospitals. We find that the diverse results in the hospital ownership literature can be explained largely by differences in authors' underlying theoretical frameworks, assumptions about the functional form of the dependent variables, and model specifications. Weaker methods and functional forms tend to predict larger differences in financial performance between not-for-profits and for-profits. The combined estimates across studies suggest little difference in cost among all three types of hospital ownership, and that for-profit hospitals generate more revenue and greater profits than not-for-profit hospitals, although the difference is only of modest economic significance. There is little difference in revenue or profits between government and not-for-profit hospitals.
\end{abstract}

\author{
Yu-Chu Shen \\ Graduate School of Business and Public \\ Policy \\ Naval Postgraduate School \\ 555 Dyer Road \\ Monterey, CA 93943 \\ and NBER \\ yshen@nps.edu \\ Karen Eggleston \\ Tufts University \\ 303 Braker Hall \\ 8 Upper Campus Rd. \\ Medford, MA 02155-6722 \\ karen.eggleston@tufts.edu
}




\section{Introduction}

The hospital industry in the United States is one of the few sectors where three different types of ownership have co-existed for decades (see Figure 1). Numerous studies investigate whether private not-for-profit, for-profit and government hospitals differ in patient outcomes, costs, provision of uncompensated care, or other measures of hospital performance. Conflicting empirical results, however, have left policymakers with little clear evidence and have limited our understanding of ownership and performance in the health sector.

Understanding whether profit status or public/private control affects performance is important for many policy issues, including how to structure public programs such as Medicare and the Veterans' Administration hospital system or how to guarantee access for the uninsured. Much of current policy governing for-profit conversions in the health care market assumes that government and not-for-profit hospitals differ from for-profits in policy-relevant ways, such as providing greater access through more uncompensated care. Anyone setting out to assess the impact of an ownership-related policy change, such as tax exemption policy for not-for-profit hospitals, immediately finds that the voluminous literature on not-for-profit, for-profit and government hospitals gives frustratingly unclear and contradictory evidence, inviting subjective and selective reference to studies that support the analysts' views.

There have been some qualitative reviews of the literature to date (Sloan 2000; Needleman 2001; Malani et al 2003). In this paper, we go beyond the qualitative approach and apply formal statistical methods used in the meta-analysis literature to synthesize quantitatively studies that investigate the effect of ownership on hospital financial performance. Specifically, we survey the literature that examined the following financial aspects: cost, revenue, profit margin, and efficiency. This paper is part of a larger project; we explore the relationship 
between other quality measures and ownership in a companion paper (Eggleston et al 2006). The primary goal of this review is to understand what factors account for the wide variation in study results, and whether there exists a consensus in the empirical evidence to indicate that ownership matters. Our emphasis on explaining variation, as well as our focus on broader outcome categories, distinguishes our study from the only precedents in the literature that perform meta-analysis related to hospital performance (Devereaux et al. 2002 and 2004).

The paper proceeds as follows. We first discuss theoretical background. Rather than a comprehensive review, this section focuses instead on a few prominent theories and summarizes theoretical predictions about how government, not-for-profit and for-profit hospitals might compare on performance measures we are examining. We then outline the methodology of our quantitative review. We present results for cost, revenue, profit margins, and efficiency, and discuss implications for policy and future research.

\section{Theoretical Background}

The comparative advantages of government and private ownership have attracted much theoretical attention and have a venerable traditional in economics (Vickers and Yarrow 1988). For example, Laffont and Tirole (1993) list several of economic theory's 'conventional wisdoms' about government ownership: government-controlled firms can take broad social welfare as their goal, and may benefit from centralized control, yet also suffer from several disadvantages. The latter include absence of capital market monitoring; soft budget constraints (Kornai 1986; Kornai, Maskin, and Roland 2003); expropriation of investments; lack of precise objectives; as well as lobbying, patronage, and politicized resource allocation (e.g. Shleifer and Vishny 1994). 
Health economists have drawn upon this general ownership debate to understand mixed ownership markets for health services. For example, according to property rights theory (Grossman and Hart 1986, Hart 1995, Hart Shleifer and Vishny 1997), since private providers (especially for-profits) have well-defined control rights, they have strong incentive to invest in innovations, but may over-emphasize cost control at the expense of noncontractible quality. By contrast, a government-owned provider lacks clear control rights to implement changes, and this constraint softens incentives for innovations. The property rights model predicts that private owners achieve lower costs, but quality may be higher or lower. Many other theories (e.g., soft budget constraints, politicized resource allocation) also predict that private for-profit providers will generally achieve lower costs for a given service than their government counterparts.

Given the prevalence of not-for-profits in the health sector, much theoretical work by health economists focuses on not-for-profit providers and how they differ from for-profit firms. Theories frequently posit that not-for-profit firms have an objective function different from that of profit maximization. Examples include maximizing quality, quantity and/or prestige (Newhouse 1970) instead of, or in addition to, maximizing net revenue (Lakdawalla and Philipson 1998); helping to fulfill demand for local public goods (Weisbrod 1988) or meet unmet need in the community (Frank and Salkever 1991); or maximizing the well-being of specific important constituencies, such as the medical staff (Pauly and Redisch 1973) or consumers (BenNer and Gui 1993). Other theories place emphasis on ownership form as an organizational choice (Lakdawalla and Philipson 1998; David 2004). In these frameworks, objectives need not differ, although the choice does sometime reflect—indeed, signals—differences in preferences. For example, organizations choosing to be bound by a nondistribution constraint have less incentive to skimp on noncontractible quality or otherwise subvert patient and community trust 
(Arrow 1963; Hansmann 1980; Glaeser and Shleifer 2001). Still other theoretical frameworks emphasize regulation and tax policies, positing that firms differ in their ability to benefit from a given ownership form (Lakdawalla and Philipson 1998; David 2004).

Since most models of not-for-profits consider objectives and/or constraints that reduce emphasis on net revenue, most such models predict—or are at least consistent with—lower costs, higher net revenue, and comparable or lower quality, of for-profits compared to not-for-profits. Yet there is no strong theoretical prediction that ownership dictates differences in performance (e.g., not-for-profits might be "for-profits in disguise"; Weisbrod 1988). Nor does theory suggest that any ownership differences will swamp other factors strongly predicted to shape behavior, such as market concentration or payment incentives. Rather, one of the strongest predictions of economic theory is that providers react to their market environment. Thus any attempt to isolate the affect of ownership on performance must address the confounding effects of market structure.

Ironically, despite a large empirical literature on hospital ownership and performance, there remains a certain disconnect between theory and evidence. Few empirical papers distinguish among economic theories of ownership form. This disconnect seems to arise for two reasons. First, many theories generate (or are consistent with) the same predictions. Second, much of the literature in health services management and clinical evaluation does not focus on testing economic theories.

Nevertheless, most empirical studies of hospital performance do "test a theory" in a broad sense: whether ownership matters for performance. Indeed, many studies that focus on other research questions, such as the volume-outcome relationship or antitrust issues, include ownership as a control variable. Apparently the majority of researchers in this field consider ownership to be a potentially important factor for explaining variation in hospital performance. 
Both studies focusing on ownership comparisons and those that merely include ownership as a control variable report widely varying results about the association between ownership and financial performance. Our review seeks to explain that variation in light of theoretical predictions about how and when ownership shapes hospital performance.

\section{Methods}

\section{Background on Meta-Analysis in Observational Studies}

As described in more detail below, we adopt meta-analytic methods to perform our quantitative review. Meta-analysis applies conventional statistical methods to combine the results from independent studies that use different data and methodologies to assess a similar research problem. Such formal statistical methods for integrating results are a staple of clinical science and have been applied successfully to many fields of economics. For example, this method was used to evaluate the effect of minimum wage laws (Card and Krueger 1995), to examine the gender gap in wages (Stanley and Jarrell 1998), to evaluate Ricardian Equivalence (Stanley 2001), and to study the determinants of enterprise restructuring in transition (Djankov and Murrell 2002). Meta-analysis has helped to clarify several controversial area of research, such as the effect of second hand smoking or the relationship between exposure to TV violence and aggressive behavior (Stanley 2001).

\section{Identifying Studies and Extracting Summary Data}

The first step of a quantitative review is to identify all relevant studies through a systematic procedure. We used a combination of the following keywords (and their variations) 
to conduct the initial search in several databases ${ }^{1}$ : hospitals, ownership, for-profit, not-for-profit, nonprofit. We limited our search to published and unpublished articles or book chapters written in English between January 1990 and July 2004. This initial search process identified 1357 potentially relevant studies.

We then applied the following selection criteria. First, we defined our study population to be general, acute, short-stay hospitals in the United States. Second, we applied an "intervention" criterion that only includes studies that compare hospitals of different ownership forms (including studies of ownership conversion, but excluding studies that only compare subcategories of ownership, such as religious vs. secular not-for-profits). Third, we limited our sample to empirical studies using multivariate analysis (i.e., excluding theoretical papers and case studies). Lastly, we confined our outcome scope to the following broad categories: financial performance (such as cost, revenue, profit margin, efficiency), patient outcomes (mortality, complication rates, or other patient outcomes), uncompensated care or community benefits, and staffing. Two authors (Eggleston and Shen) independently applied the above selection criteria to identify the relevant studies for our project. ${ }^{2}$ After we identified this initial set of relevant studies, we contacted the corresponding authors of all included papers to solicit any unpublished papers that might fit our project scope. We received responses from authors that resulted in 77 additional studies. We applied the same selection criteria again to this new set of studies. At the end of this search and selection process, we identified 141 studies for our quantitative review. Figure 2 summarizes our selection process.

In this paper, we report findings from the financial performance quantitative review.

\footnotetext{
${ }^{1}$ The databases included Medline, EconLit, and Proquest/ABI (for dissertations). We also identified studies through work cited in the literature or previous qualitative reviews (e.g., Zeckhauser, Patel and Needleman 1995 is an unpublished report to a Foundation).

${ }^{2}$ Throughout the coding process we found a discrepancy in our independent coding of only $7 \%$; all differences were reconciled by consensus after joint review.
} 
Among the 141 relevant studies, 67 focus on financial performance. Many studies analyze multiple measures of financial performance. Conversely, many specific performance measures are analyzed only by a few studies. Since we need an adequate sample size to be able to apply meta-analytic methods, we only review outcomes that are analyzed by at least 10 studies. The four most commonly studied financial outcomes that we review extensively are: hospital cost, revenue (including returns on assets), profit margin, and efficiency (including both cost and technical efficiency).

Data extraction. For each included study, we extracted study information into a predefined abstraction form that covered the following sets of information: data sources, sampling frame (covered years, covered regions, sample size), detailed outcome definition, ownership coefficients and their associated statistics (such as standard errors, t-statistics, p-value, degrees of freedom of the model), and empirical methods. We coded empirical methods using the following set of binary variables: whether the study included patient demographic characteristics, patient severity of illness information (such as a case mix index), hospital-level characteristics (such as bed size, share of Medicare and/or Medicaid admissions), and market-level characteristics (such as per capita income, population size, hospital market characteristics), and whether ownership is only included as a control variable. In addition, we categorized each study's methodology by coding whether the study employs panel data estimation methods, whether the study explicitly models certain market interactions that can potentially bias the ownership estimates (such as explicit adjustment for selection through Heckman or instrumental variables, or explicit control for intensity of hospital competition), and the functional form of the dependent variable (e.g., log transformation, average measure, or other definition). For efficiency studies, there is an ongoing debate about the merit of data envelopment analysis and 
the stochastic frontier regression approach. We extracted information from the efficiency studies about how they applied these two methods.

Expert panel. To provide additional guidance on the research questions and analytic strategies, we recruited thirteen prominent researchers in the area of hospital ownership and performance to serve on our expert panel. ${ }^{3}$ These individuals gave input on issues ranging from the big picture questions to specific analytic methods for explaining and quantifying differences among studies.

\section{Statistical Methods}

A typical study estimates the impact of ownership on performance as follows:

$$
Y=\alpha+\beta_{1} F P+\beta_{2} G O V+\gamma X+\xi .
$$

$\mathrm{Y}$ is a measure of hospital financial performance, FP indicates for-profit ownership, GOV signifies government ownership (the omitted group is not-for-profit ownership-NFP), $\mathrm{X}$ is a vector of hospital and market characteristics, and $\xi$ is the error term. If estimated properly, the coefficients $\beta_{1}$ and $\beta_{2}$ capture the average effect on $Y$ of for-profit and government ownership, respectively, relative to not-for-profit ownership. However, as with any observational studies, unobserved factors could lead to biased estimates of the coefficients. We provide details below on classifying studies based on the extent to which study methods can reduce this potential bias. In this section, we describe the methods used to answer the three questions of our quantitative review:

1. What is the magnitude of the relationship between ownership and financial performance — what is the "effect size" of each study?

\footnotetext{
${ }^{3}$ We invited researchers to serve on the expert panel based on the number of studies included in our list that they had co-authored, their areas of expertise, recent work in the field, and availability and willingness to serve on the panel. We thank their contribution. The names of our expert panel are listed in the acknowledgement section.
} 
2. How precise or reliable is this estimated effect size?

3. How do differences in analytic methods and other study features affect the estimates of effect size?

We first discuss how we define and compute the effect size for our review. We then describe the meta-regression procedure used to explore how differences in study features lead to different conclusions about ownership's effect on financial performance. We finally consider empirical issues that arise when applying meta-analytic methods to the hospital literature.

Defining effect size. To synthesize and compare studies, we must first develop a summary measure of each study's results, an "effect size," that can be compared across studies. In randomized clinical trials where meta-analytic methods are often applied, the effect size is simply the difference in average outcome between the treatment and the control group, divided by the appropriate standard deviation. However, all hospital ownership studies are observational studies that use some form of multivariate analysis. Intuitively, the coefficients $\beta_{1}$ and $\beta_{2}$ capture the effect size of for-profit and government ownership, relative to not-for-profit ownership, respectively. However, the magnitude of $\beta$ 's depends on the units of the dependent variable, which vary considerably because studies measure the same financial outcome differently. For example, some studies measure cost in dollars, while others transform the cost measure to logarithmic form.

Another possible metric is the t-statistic associated with the ownership coefficient estimate, which is unit-free. However, the magnitude of the t-statistic increases proportionally with the square root of the sample size. This dependence on sample size suggests that t-statistics are not the appropriate measure for the economic magnitude of ownership differences.

To define an effect size that is unit-free and does not depend on sample size, we use the 
partial correlation coefficient (Rosenthal 1991). A partial correlation coefficient measures the correlation between a given ownership form and performance measure $\mathrm{Y}$, controlling for the effect of covariates X. Although most studies do not report partial correlation coefficients, they can be computed using statistics that are commonly reported in published studies (Greene 1997):

$$
r^{*}=\sqrt{\frac{t_{F P}^{2}}{t_{F P}^{2}+\text { degrees of freedom }}} .
$$

One concern is that the distribution of $\mathrm{r}^{*}$ becomes more skewed as the population value of $\mathrm{r}^{*}$ gets further away from zero. We therefore adopt a standard practice in meta-analysis:

standardizing the effect size by applying the Fisher transformation, which is distributed nearly normally (Hedges and Olkin 1985):

$$
Z_{r}=\frac{1}{2} \log \left[\frac{1+r}{1-r}\right]
$$

One thing to note is that our conclusions are not sensitive to whether we standardize the effect size or not. We then compute the confidence interval around the effect size to answer our second research question (see the appendix for details).

After comparing effect sizes across studies, the next common step is to summarize the literature by combining the effect sizes across studies. We intentionally leave out the combined effect size information from this paper. It is tempting to view the combined effect size as a summary measure of whether the empirical literature as a whole predicts ownership to be a significant factor in affecting hospital financial performance. However, as we will discuss in more detail below, studies in the hospital ownership literature usually have overlapping samples and data sources. This implies that the statistical power of our quantitative review does not increase proportionally with the sample size of each additional study; thus, the precision of the combined effect size will be overstated. Instead, we focus on explaining the variation in effect 
sizes across studies through the meta-regression approach described below.

Explaining Variation in Study Results. To answer our third question-how do study features affect the estimated ownership effect size? — we categorize studies' methodology and employ meta-regression analysis. These approaches allows us to examine whether study features such as analytic methods, functional forms, or region studied can explain differences in effect sizes across studies. For example, do studies that control for market-level confounding factors such as intensity of competition find larger or smaller effects of ownership per se on financial performance than studies that do not control for such confounding factors?

The included studies vary widely in analytic methods. Given the limited number of studies in each financial outcome category, it is necessary to categorize the diverse methods in a concise way. With input from our expert panel, we classified studies into the following three categories:

- $\quad$ Type III: if the study meets both of the following conditions:

(a) uses panel estimation or otherwise explicitly accounts for the potential unobserved factors in the estimation model (such as by using instrumental variables);

(b) includes two of the following three sets of controls: patient level, hospital level, or market level;

- $\quad$ Type II: if the study meets either condition (a) or (b) ${ }^{4}$;

- $\quad$ Type I: if the study meets neither condition (a) nor (b).

We then can compare differences in effect sizes and their precision according to methodological classification.

This 3-tier classification is designed to capture how many unobserved factors might

\footnotetext{
${ }^{4}$ In the studies we reviewed, only one study meets criteria (a) but not (b). Therefore Type II method basically includes all cross-sectional studies that meet criteria (b), i.e., include controls at the hospital, market, and/or patient level.
} 
remain to bias the estimated ownership effect. Recall that in general, studies estimate the average effect of ownership, i.e., $\beta_{1}$ and $\beta_{2}$ in eq (1), which might be biased by the presence of unobserved factors. Type III studies control for the most confounding and thus have the fewest unobserved factors; Type I studies lack many control variables and thus are likely to have the most unobserved factors biasing the ownership estimates. Panel estimation methods are included as Type III studies, because these methods, such as fixed-effects models, are usually viewed as appropriate tools to eliminate bias arising from time-invariant unobserved factors.

Another interpretation is that the 3-tier classification captures the broadness of the causal effect. There are various mechanisms through which ownership matters in affecting hospitals' financial performance: for-profit hospitals might pursue healthier patients or select a location with a wealthier population. If a study controls for both patient characteristics and market characteristics (such as Type III studies), then it essentially estimates a very narrow effect of ownership - it compares for-profit and not-for-profit hospitals assuming that both have comparable patient populations and market characteristics. Thus one can view Type I studies as estimating the broadest causal effect_-including location choice, market competition and other factors with ownership — and Type III studies as estimating the narrowest causal effect.

To assess the importance of methodology as well as other factors in explaining variations in study results, we conduct meta-regressions. The dependent variables in our meta-regressions are the standardized effect sizes from each study. The explanatory variables are the empirical features of each study. The model is necessarily parsimonious, since there are only a few studies for each measure of financial performance, and many study features are highly collinear (correlation matrices of study features are included in the appendix). Because our sample size is small for each outcome category, we examine different types of study features in separate meta- 
regressions.

- In the first set, we focus on analytic methods, using indicator variables for the 3-tier method classification defined above. In addition, we include an indicator of whether ownership is only included as a control variable and not the focus of the study.

- The second set of meta-regression focuses on the functional form of the dependent variables. Differences in functional forms reflect authors' underlying assumptions about cost and revenue structure. For example, among the 18 cost studies comparing not-forprofit and for-profit hospitals, 3 examine the dollar value of cost per discharge, 11 analyze the log transformation of cost measures, and the remaining 4 studies use other cost definitions. Similarly for revenue studies, some compare for-profit and not-forprofit hospitals' revenue in dollars per discharge, while others compare the differences in percentages. To examine whether these differences in specification of the dependent variable affect conclusions regarding ownership and performance, we create an indicator that takes on the value of 1 if the dependent variable is log transformed and 0 otherwise. For the efficiency studies, some authors assume that efficiency follows a deterministic model (data envelopment model) while others allow for random errors (stochastic frontier model). We create an indicator to differentiate these two approaches.

- The third set of meta-regressions focuses on the regions covered. In particular, we are interested to know whether single-state analyses differ substantially from analyses that use national samples.

- The last set of meta-regressions examines the sources of data. In particular, we categorize studies based on whether they use administrative data only (such as Medicare hospital cost reports or state department of health hospital data), survey data only (such 
as AHA surveys), or use both types of data. Concerns with survey data include record accuracy and attrition. However, survey data usually contains a richer set of information.

Issues in quantitative review of the hospital ownership literature. Most meta-

analyses of clinical trials ask how well a treatment works overall. The traditional meta-analytic methods are designed to answer the same question in the same population. In those cases, a fixed-effects model is used to combine effect sizes across studies, which assumes that there is one single underlying true effect. However, in our case the research questions are not homogeneous even within a narrowly defined financial outcome group. It is worth noting that with our selection strategy, we include not only studies whose research question focuses on the relationship between financial performance and ownership, but also studies that answer some other research questions about hospital finance that include ownership as a control variable in their multivariate analyses. Because of the heterogeneity of research questions and results, we use a random-effects model for the meta-regression. The random-effects model assumes no single true effect, but rather that there is an underlying distribution of this true effect, commonly assumed to follow a normal distribution (Lau et al. 1998). The random-effects model assumes there is between-study variation in addition to within-study variation around the estimated effect size; therefore, the confidence intervals constructed under a random-effects model are larger than under a fixed-effects model.

Another issue in integrating the studies is that not all studies report the necessary statistics. In many instances, particularly for policy journals, authors report only the significance level of the coefficient. We contacted the corresponding authors to get the exact t-statistics where possible. In cases where we could not get the exact number, we estimate the t-statistic by 
generating a random number within the reported significance range. ${ }^{5}$

Unlike meta-analyses of clinical trials, where the sample in each study comes from mutually exclusive patient populations, many studies we reviewed analyzed the same set of hospitals in overlapping years. There are fewer than 5000 general acute hospitals in the US. As Table 1 shows, many studies analyze national samples, and most studies use one of two common data sources: either the American Hospital Association Annual Survey or the Medicare Hospital Cost Reports (also known as Healthcare Cost Report Information System, HCRIS). Our effect size measures, defined by partial correlation coefficients, should remain valid when observations are correlated (Rosenthal 1991). However, the studies do not represent independent samples, and statistical power will not increase proportionally with each additional study's sample size even if we pool studies. Therefore we do not report the combined effect size since the precision of such measure would be overstated.

The non-independent nature of study samples sits at odds with the assumption behind the traditional meta-analysis. However, we believe applying the meta-analytic methods to our quantitative review still provides valuable insight. By comparing studies on a common metric (i.e., the standardized effect size) and characterizing methods, we are able to decipher how methodological differences influence study results.

Nevertheless, we stress that our results are most valuable for explaining variation, not for providing "one true answer" about how ownership affects financial performance. It should also be noted that the meta-regression approach cannot predict a specific hospital's performance. But our analysis does suggest what study designs are most likely to predict performance differences

\footnotetext{
${ }^{5}$ For example, a study might report results significant at the $0.01,0.05$, and 0.10 levels. If the ownership coefficient is not statistically significant, the estimated t-statistic is a random number between 0 and 1.64 . If the ownership coefficient is significant at the 0.10 level, the estimated t-statistic will be a random number between 1.64 and 1.96; and so on.
} 
by ownership form, and suggest ways in which future research should get into the "black box" of hospital performance variation.

\section{Results}

Table 1 summarizes the studies included in this quantitative review. Many studies analyze multiple financial outcomes. Among the 40 included studies, 25 analyze a broad sample of hospitals (either a national sample or hospitals in MSAs, which account for over 55 percent of US community hospitals). Half of the studies utilize multiple years of data, and the studied years range from 1981 to 1998 .

Table 2 presents the percentage of studies with each study feature that we included in the meta-regression. The top panel shows the features of studies that compare not-for-profit with for-profit ownership; the bottom panel describes studies that compare not-for-profit with government ownership. The share of studies with a given feature varies across the four financial outcomes. The top panel shows that the percent of studies classified as Type III methods ranges from 21 percent for efficiency studies to 44 percent for cost studies. About 40 percent of studies do not focus on ownership but include this information in their models. Sixty-one percent of cost studies analyze log-transformed cost, whereas only 27 percent of revenue studies analyze the log-transformed version of revenue. Among efficiency studies, 32 percent assume a deterministic model while the rest assumes a stochastic frontier model. Many of these study features are highly correlated. We include the correlation among these study features for each outcome category in the appendix. For example, those that studied California hospitals are also likely to be Type I (with correlation of 0.77-0.79, depending on the outcome studied); except for studies of efficiency, Type III studies tend to utilize both administrative and survey data (with correlations ranging from $0.34-0.55)$. 
The sample size of our quantitative review shrinks considerably when we look at studies that compare not-for-profit and government ownership (bottom panel of Table 2). Generally these studies are a subset of the ones that compare not-for-profit and for-profit ownership.

Review of Cost Studies. There are 18 studies that analyze cost differences between forprofit and not-for-profit hospitals. Five studies examined total cost (which includes both operating cost and capital cost) while the other 13 studies used operating cost as the dependent variable. We first summarize the effect sizes of for-profit ownership compared to not-for-profit ownership of hospitals (Figure 3A). We group the studies by the methodology type. Figure 3A also reports the confidence intervals around each study's effect size. ${ }^{6}$

Figure 3A shows that the effect size ranges from -0.23 (indicating that for-profits have lower cost than not-for-profit hospitals) to +0.27 (indicating for-profit hospitals have higher costs than not-for-profit hospitals). Except for the Type I studies, most studies have relatively small effect sizes. The three Type I studies are all studies using data from a single state and cover only a single year. The study with the largest negative effect also analyzed data from just one state (Florida).

Figure 3B summarizes the effect sizes for studies comparing not-for-profit and government hospitals. A negative effect size indicates that government hospitals operate at lower cost than their not-for-profit counterparts. The variation in effect sizes across studies is even smaller than that between not-for-profit and for-profit hospitals.

The standardized effect size that we use provides less intuitive interpretation of the ownership effect for clinical or policy decisions. One way to interpret the effect sizes is through

\footnotetext{
${ }^{6}$ Several studies analyze different years and/or states separately, and thus have multiple effect sizes (one corresponding to each year or state estimate). For the summary plot in Figure 3 and similar plots for other performance measures, we average the multiple effect sizes so that we report one effect size per study, and adjust the standard error of the effect size to reflect the total sample size used in that particular study.
} 
the $\mathrm{r}^{2}$, which represents percent variation explained by the ownership indicator. As Figure 3A shows, even the study with the largest effect size (0.27) would only account for 7 percent of the study variation. In addition, by the conventional Cohen standard, magnitudes of our effect sizes mostly fall into what is considered the "small" effect region $(\mathrm{r}<0.10)$, indicating that ownership appears to play a much less important role in influencing hospital performance than other hospital characteristics, even when it is a significant predictor. This result is not surprising, given that there are so many other factors influencing a hospital's operations. .

The economic significance of this cost difference seems small. Consider, for example, an alternative way to illustrate how modest the ownership effect size is, by comparing the ownership effect to that of teaching status, size, and urban/rural location. In one Type III paper (Carey 1997), the comparable effect size for "heavy teaching" hospital cost (compared to nonteaching hospital cost) is more than five times that of the ownership effects, and the effect size for "large urban" is more than three times the magnitude of the ownership effects.

In Table 3, we analyze what study features might drive differences in ownership effect sizes across studies that compare not-for-profit and for-profit hospitals. We report the metaregression results of cost studies in the first column. ${ }^{7} \quad$ In all cases the chi-square test for heterogeneity clearly rejects the null hypothesis that our combined studies are a homogeneous set (data not shown), thus validating our approach of using random effects regression models in our meta-regressions. ${ }^{8}$ The analytic method regression (first panel) clearly indicates that the ownership effect diminishes as we move from studies that estimate the broadest causal effect (Type I) to ones with the narrowest causal effect (Type III). In other words, studies that control

\footnotetext{
${ }^{7}$ Unlike the summary plot where only one averaged effect size is associated with each study, we include all effect sizes from each study in the meta-regression; hence Tables 3 and 4 show larger sample sizes in some categories than in the corresponding figures.

${ }^{8}$ If we do not reject the test of heterogeneity, then there is no need to conduct a meta regression.
} 
for a wider range of confounding factors find less difference in cost between for-profit and notfor-profit hospitals. Studies that focus on a research question other than ownership are no different from ones that focus on ownership, after controlling for methodology. The last row of the first panel indicates that 93 percent variation in the standardized effect size is due to heterogeneity in methodology.

The second panel of Table 3 shows that functional form matters as well. Studies without $\log$ transformation of the dependent variable tend to produce larger effect sizes. Given that healthcare costs are highly skewed, it would appear that log transformation is warranted. Studies that use log of cost as the dependent variable tend to find no significant difference in cost between for-profit and not-for-profit hospitals.

Effect sizes vary widely between studies using data from different parts of the country. While California and Florida tend to produce larger and negative effect sizes that indicate forprofit hospitals have lower costs in those states, studies of Virginia's for-profit hospitals suggest they have higher costs than their not-for-profit counterparts. However, it should be noted that the two studies using Virginia data (Shukla 1997 and Wang et al. 2001) are both classified as Type I method and both have very wide confidence intervals around the effect sizes due to small numbers of hospitals included. The limited sample size of our meta-regression precludes us from ascertaining whether the larger effect size of these studies derives from state differences, urban/rural mix of hospitals, analytic methods, or some combination of the above factors. We also examine whether differences in effect sizes can be explained by the authors' choice of total cost or operating cost; we do not find any significant differences (results not shown). The last panel of Table 3 shows that studies using survey data only tend to find a larger gap in cost between not-for-profit and for-profit hospitals. However this study feature is highly collinear 
with the functional form: the 4 studies that use only survey data all estimated the ownership effect using the actual cost without log transformation.

Table 4 reports meta-regressions exploring what study features explain differences among studies that compare government hospitals to not-for-profit hospitals. Since the variation in effect sizes is much smaller than that between not-for-profits and for-profits, we do not find much difference in effect size as we compare across analytic methods, functional form of the dependent variable, or regions. The only significant study feature is that studies whose research focus is not on ownership tend to find government hospitals less costly than not-for-profit hospitals.

Review of Revenue Studies. Among the 11 studies that examine revenue differences between for-profit and not-for-profit hospitals, 4 studies analyze returns on assets, 2 examine total revenue, and the rest focus on net patient revenue. Figure 4A summarizes the effect sizes for studies on revenue and returns on assets, categorizing studies by their methods. Unlike cost studies, where there is a wide range of effect sizes from negative to positive numbers, all revenue studies report either no difference between for-profits and private not-for-profits, or a positive effect size, indicating that for-profits earn greater revenue. But similar to the cost studies, Type I studies estimate much bigger for-profit effect than Type II and Type III studies. The three Type I studies have small sample sizes, as reflected by the wider confidence intervals around the effect sizes.

Only four studies examine revenue differences between not-for-profit and government hospitals (Figure 4B). All of them find little or no revenue difference between the two ownership forms.

The second column of Table 3 reports the meta-regression results for revenue studies 
comparing not-for-profit and for-profit hospitals. Similar to the cost studies, the magnitude of the effect size shrinks substantially as we move from Type 1 to Type III studies. Type I studies tend to find for-profits earn substantially higher revenue than not-for-profits. The more control there is for confounding factors, the less likely a study will find differences between for-profits and not-for-profits.

Similar to cost studies, studies without log transformation of the dependent variable tend to produce larger effect sizes.. Studies analyzing California and Virginia hospitals tend to produce larger effect sizes than studies using a national sample. However, all 4 studies of California and Virginia use Type I methods. Since these two state indicators are perfectly collinear with the Type I method indicator, we cannot separate out the state effect from the effect of analytic methods. We do not perform meta-regressions to explain variations in revenue between not-for-profit and government hospitals due to limited sample size.

Review of Profit Margin Studies. Among the financial performance measures studied, profit margin has the most consistent definition across studies. Virtually all 14 studies that examine profit margins of for-profit and not-for-profit hospitals define profit margin as the difference between revenue and cost divided by revenue. All studies find either no difference or that for-profit hospitals earn higher profit margins than not-for-profit hospitals do (Figure 5A), with the Type I studies finding larger effects than others. The effect size ranges from -0.09 to +0.28 (the two studies with negative effect sizes both have confidence intervals that include zero). Given that there appears to be little cost difference between the two private ownership forms, our results would suggest that the higher profit margins of for-profit hospitals derive from their higher revenues. In contrast, Figure 5B shows that among the 6 studies that examine profit margin differences between not-for-profit and government hospitals, 4 found no differences 
while the remaining 2 studies found opposite effects. (Shen 2003b, which found a positive effect, studied conversion of not-for-profits to government ownership.) The effect sizes are smaller than those in Figure 5A and statistically insignificant, indicating smaller differences between not-for-profits and government-owned hospitals than between not-for-profits and for-profit hospitals.

The meta-regression results in Table 3 once again show that analytic methods can explain much of the between-study variation in estimates of how much net revenue for-profits earn relative to not-for-profit hospitals. Ninety-three percent of the variation in the standardized effect size can be attributed to the heterogeneity across studies. Type II and Type III methods produce similar effect sizes; both tend to find much smaller effect sizes than those estimated with Type I methods. In other words, studies that control for more confounding factors - particularly market competition - tend to find less of a profit margin advantage of for-profits over not-for-profits. The two studies of Virginia hospitals report much larger profit differences than the other studies (as for cost and revenue), but they also have the largest confidence intervals around their effect sizes. Similar to cost studies, studies using only survey data tend to find a larger gap in profit margin between not-for-profit and for-profit hospitals. Unlike cost studies, this study feature is not strongly correlated with other study features (all correlations were below 0.32 ). We do not find any study features that can explain variation in study findings about net profits earned by government and not-for-profits ( $2^{\text {nd }}$ column in Table 4$)$, likely because there is less variation to explain.

Review of Efficiency Studies. Measuring hospital efficiency has been a controversial area of the hospital ownership literature (for example, see the discussion in the 1994 volume 14 
issue of the Journal of Health Economics). ${ }^{9}$ In addition to estimating hospital cost functions (as discussed above), there are two methodologies that researchers often employ: data envelopment analysis (DEA) and stochastic frontier regression (SFR). SFR analysis incorporates data on input prices, and measures efficiency as least cost production (in other words, it measures efficiency from all sources of cost), whereas DEA uses data on inputs and outputs, and measures efficiency as the least amount of input for a given amount of output (this is referred to as technical efficiency, and is considered a subset of cost efficiency). Both approaches make inferences about efficiency from a residual. The major empirical difference between the two approaches is that SFR assumes the residual term reflects both inefficiency and random factors, while DEA is a purely deterministic model that assumes all departures from the best-practice frontier reflect inefficiency. DEA offers the advantage of being relatively flexible in modeling the underlying production technology but makes no adjustment for random error. There is a concern that DEA analysis is only useful when the sample size is very large (about 1,000 observations or more), and that the deterministic nature of the model does not suit the hospital industry. SFR explicitly models random error, but it also assumes a structure for the underlying production technology. In either case, wrong assumptions about the functional form, misspecification of the models or omitted variables could easily bias the results.

In our quantitative review, we include both cost efficiency and technical efficiency since one is the subset of the other, and this allows us to compare studies using DEA and SFR approaches. In Figure 6, we group the effect sizes by whether the study analyzed a single state or a broader sample. ${ }^{10}$ Figure $6 \mathrm{~A}$ shows that the 4 studies that analyze single states ( 3 Florida studies and 1 Washington study) all find for-profit hospitals to be more efficient than not-for-

\footnotetext{
${ }^{9}$ We especially thank our expert panel for providing input on this topic.

${ }^{10}$ We chose this way to display effect sizes to reflect what the meta-regression found to be significant in explaining variation between studies.
} 
profit hospitals. In contrast, 7 out of 9 national studies find for-profits to be less efficient than not-for-profit hospitals.

The last column of Table 3 shows that effect sizes do not vary that much across the three categories of analytic methods. However, studies that do not focus on ownership (36\%) tend to report for-profits to be more efficient than not-for-profit hospitals. DEA models also produce larger effect sizes than SFR. The Florida effect shows up in the third panel of Table 3, suggesting that for-profit hospitals are more efficient than not-for-profit hospitals in Florida. Since effect sizes do not appear to differ across studies using different methodologies, we can infer that this large effect size in Florida — suggesting that for-profits are more efficient than notfor-profits - is not driven by methodological differences, although it does rely on just three studies. We do not find data types to explain the variation in study results.

Comparison between not-for-profit and government hospitals in general finds little consistent efficiency difference between these two ownership forms (Figure 6B). Estimates based on Florida data tend to find government hospitals more efficient than their not-for-profit counterparts, although again this result derives from just two studies, and cost function estimates do not find a similarly significant "Florida effect." This study feature is also highly correlated with the use of administrative data. Not surprisingly, we find studies using only administrative data tend to find government hospitals more efficient than not-for-profit hospitals. Without more studies, we cannot separate out the Florida effect from the data source effect for the comparison between not-for-profit and government hospitals.

\section{Publication Bias and Sensitivity Analysis}

The potential for publication bias has received substantial attention in quantitative 
reviews in both the clinical literature as well as some in other areas of economics (e.g., estimates of the effects of the minimum wage on employment as discussed in Card and Krueger 1995). The concern is that published results may be biased, because published studies are less likely to include negative results (e.g. for clinical trials) or results not supporting a strong theoretical prediction (e.g., about how the minimum wage reduces employment for low-wage workers). A priori we might suspect less concern with such bias in the hospital ownership and performance literature. As noted in the background section, some theories and previous evidence suggest little difference in behavior between ownership forms. Many, but not all, studies of hospital performance include ownership as a control variable even if it is not the key variable of interest, suggesting that researchers do not all agree on whether ownership per se is an important confounder of other hospital performance results.

Following the approach by Card and Krueger (1995), we test the existence of publication bias by examining the relationship between the absolute value of $\mathrm{t}$-statistics and the square root of degrees of freedom. Figure 7 clearly shows that the t-statistics increase with the degrees of freedom; we do not see a pattern in which most t-statistics hover around 2 regardless of sample size. Consistent with our expectation, we conclude that there is no evidence of publication bias in this literature.

Two of the studies (Zeckhauser, Needleman, and Patel 1995; Ferrier and Valdmanis 1996) separately analyze sub-groups of for-profit hospitals, those that belong to larger systems and those that are independent. (Both types of for-profit are compared to not-for-profit hospitals). In our main review, we use the reported ownership effects from the for-profit chains; in our sensitivity analysis, we use the information from for-profit independent hospitals. The overall results are very similar, and conclusions remain the same. Our conclusions are also robust to 
separating cost efficiency from technical efficiency.

Disease-specific analyses are often better equipped to avoid confounding from differences in mix of services provided and to control for differences in patient case mix and severity. In sensitivity analyses for the hospital cost review, we include additional studies of cost in which the dependent variable is not the broad hospital operating cost. These additional studies include some that analyze cost associated with specific disease treatment (such as heart attacks, asthma, or hysterectomy) and studies of Medicare payments. ${ }^{11}$ These additional studies also have relatively small effect sizes with no significant differences between for-profits and notfor-profits. We focus on the present set of 18 studies to have a relatively homogenous set of dependent variables.

\section{Discussion}

We conduct a systematic quantitative review of the empirical literature since 1990 comparing financial performance of US not-for-profit, for-profit, and government-owned general acute hospitals. The salient point from this quantitative review is that the diverse results in the hospital ownership and performance literature derive largely from differences in authors' underlying theoretical frameworks, assumptions about the functional form of the dependent variables, and model specifications. Methods that control for fewer factors and less appropriate functional forms tend to predict larger differences in financial performance between not-forprofits and for-profits.

More specifically, studies that control for a wider range of confounding factorsincluding at the patient, hospital, and market levels or using panel data estimation techniquesfind smaller differences in financial performance between for-profit and not-for-profit hospitals.

\footnotetext{
${ }^{11}$ The additional studies are Ettner et al. (2001), Huang et al. (2002), Kessler and McClellan (2002), Sloan et al. (1999), and Bazzoli (2004).
} 
Studies that use a logarithmic transformation of cost and revenue for those dependent variables, as their skewed distributions suggest is appropriate, tend to find no significant difference between for-profit and not-for-profit hospitals. This is true for cost, revenue, and profit margin comparisons. For efficiency studies, the meta-regression suggests that methodological differences play less of a role in explaining the variation in findings than differences in geographic region.

There are various mechanisms through which ownership matters in affecting hospitals' financial performance: for-profit hospitals might pursue healthier patients or selectively locate near a wealthier population. While all studies are essentially estimating the average effect of forprofit and/or government ownership, one can view the difference between Type I and III studies as the difference between broad and narrow ownership effects. Type III studies are estimating ownership effects assuming all hospitals have comparable patient populations and market conditions (i.e., such studies are designed to disentangle ownership from the effects of patient case-mix, market competition, and other confounding factors). Type I studies include within the estimated ownership effect market conditions and revenue seeking behaviors that can potentially affect the patient mix. For most financial performance measures, the estimated differences between for-profit and not-for-profit hospitals vary significantly between studies using data from different regions of the country. Single-state studies, primarily from the south and west, tend to find larger differences between for-profit and not-for-profit hospitals. Unfortunately, with the exception of efficiency studies, it is difficult to disentangle what drives these differences, partly because state-specific analyses often use Type I method and/or only a single year of data, so that regional differences are confounded by differences in analytic methods.

Even though our quantitative review provides some insight on what the magnitude of the 
ownership effect might be overall, such findings must be interpreted with great caution. Studies in this literature do not represent independent estimates of the "treatment" effect of ownership on performance. Most draw from two widely used sources of data, and many analyze overlapping regions and years, so that the same hospitals and patient populations underlie estimates from different studies. Ideally, one can implement a quasi Durbin-Watson test of serial correlation or impose a certain covariance structure on the meta regression estimations. However, the statistical properties of such approaches are not well understood in the context of meta analysis, and their development is beyond the scope of this project. Given increasing interest in quantitative review of the health services research literature, developing this set of tools to address overlapping samples in quantitative reviews would be valuable future work.

Even though we do not combine effect sizes to provide one summary statistic as commonly done in traditional meta-analysis, we do see some consistency in findings across studies, especially for revenue and profit margins. Even though evidence to date suggests little difference in cost among all three types of hospital ownership, studies that compared revenues all found either that for-profits earn greater revenue and higher profits or that there is no difference between for-profits and not-for-profits. There is less clear evidence of a difference in revenue or net revenue between government and not-for-profit hospitals.

It is not surprising that for-profits tend to earn more profit: that is their mission, and is the prediction of virtually all economic models that contrast for-profit and not-for-profit behavior. However, the conventional wisdom that for-profit hospitals would operate more efficiently (i.e., at lower cost) was not supported in this review. Overall, the dispersion and inconsistency of estimates about how ownership form correlates with financial performance mirrors the larger question of what drives wide variations in performance across hospitals of the same type (e.g. 
McClellan and Staiger 2001). Future research can be most fruitful if it goes beyond the standard administrative datasets to explain this wide variation in performance both with more in-depth data about the "black box" of hospital decision-making and with analysis of market spillover effects. Our current exploration of the literature between non-financial performance measures and hospital ownership would provide further insight about ownership behavior differences. Evidence from other countries can also contribute significantly to furthering our understanding of ownership and behavior. 


\section{Bibliography}

\section{Studies Included in the Quantitative Review}

Bazzoli, G. J., B. Chan, S. M. Shortell, and T. D'Aunno. "The Financial Performance of Hospitals Belonging to Health Networks and Systems." Inquiry 37, no. 3 (2000): 234-252.

Bazzoli, Gloria J., Richard C. Lindrooth, Romana Hasnain-Wynia, and Jack Needleman. "The Balanced Budget Act of 1997 and U.S. Hospital Operations." Inquiry 41, no. 4 (2004): 401-417.

Becker, E. R., and S. J. Potter. "Organizational Rationality, Performance, and Social Responsibility: Results from the Hospital Industry." Journal of Health Care Finance 29, no. 1 (2002): 23-48.

Brown, H., and I. I. I. Shelton. "Managed Care and Technical Efficiency." Health Economics 12, no. 2 (2003): 149-158.

Burgess, James F. Jr, and Paul W. Wilson. "Hospital Ownership and Technical Inefficiency." Management Science 42, no. 1 (1996): 110-123.

Campbell, E. S., H. Xiao, and M. K. Smith. "Types of Hysterectomy. Comparison of Characteristics, Hospital Costs, Utilization and Outcomes. " Journal of Reproductive Medicine 48, no. 12 (2003): 943-949.

Campbell, Ellen S. "Hospital Efficiency and Indigent Care." Applied Economics 22, no. 11 (1990): 15971610.

Carey, Kathleen. "Hospital Cost Containment and Length of Stay: An Econometric Analysis." Southern Economic Journal 67, no. 2 (2000): 363-380.

Carey, Kathleen. "A Panel Data Design for Estimation of Hospital Cost Functions." Review of Economics and Statistics 79, no. 3 (1997): 443-453.

Chan, B., R. Feldman, and W. G. Manning. "The Effects of Group Size and Group Economic Factors on Collaboration: A Study of the Financial Performance of Rural Hospitals in Consortia." Health Services Research 34, no. 1, Part 1 (1999): 9-31.

Chirikos, Thomas N., and Alan M. Sear. "Measuring Hospital Efficiency: A Comparison of Two Approaches." Health Services Research 34, no. 6 (2000): 1389-1408.

Chrikos, Thomas N., and AM Sear. "Technical Efficiency and the Competitive Behavior of Hospitals." Socio-Economic Planning Sciences 28, no. 4 (1994): 219-227.

Connor, Robert A., Roger D. Feldman, and Bryan E. Dowd. "The Effects of Market Concentration Horizontal Mergers on Hospital Costs and Prices." International Journal of the Economics of Business 5, no. 2 (1998): 159-180.

Eggleston, K., Schmid, C. and Lau, J., Chan, J. and Shen Y. "Systematic review of hospital ownership and quality of care: what explains the different results in the literature?" 2006. Manuscript. 
Ettner, Susan L., and Richard C. Hermann. "The Role of Profit Status Under Imperfect Information: Evidence from the Treatment Patterns of Elderly Medicare Beneficiaries Hospitalized for Psychiatric Diagnoses." Journal of Health Economics 20, no. 1 (2001): 23-49.

Ferrier, Gary D., and Vivian Valdmanis. "Rural Hospital Performance and its Correlates." Journal of Productivity Analysis 7, no. 1 (1996): 63-80.

Folland, S. T., and R. A. Hofler. "How Reliable are Hospital Efficiency Estimates? Exploiting the Dual to Homothetic Production." Health Economics 10, no. 8 (2001): 683-698.

Fournier, Gary M., and Jean M. Mitchell. "New Evidence on the Performance Advantages of Multihospital Systems." Review of Industrial Organization 12, no. 5-6 (1997): 703-718.

Gapenski, L. C., W. B. Vogel, and B. Langland-Orban. "The Determinants of Hospital Profitability." Hospital and Health Services Administration 38, no. 1 (1993): 63-80.

Gautam, K., C. Campbell, and B. Arrington. "Financial Performance of Safety-Net Hospitals in a Changing Health Care Environment." Health Services Management Research 9, no. 3 (1996): 156171.

Goes, J. B., and C. Zhan. "The Effects of Hospital-Physician Integration Strategies on Hospital Financial Performance." Health Services Research 30, no. 4 (1995): 507-530.

Hogan, Andrew J., and Roger Wroblewski. "The Determinants of Hospital Efficiency: A Data Envelopment Analysis." Public policy applications of management science. (1993): 115-144.

Huang, Z. J., B. J. LaFleur, J. M. Chamberlain, M. F. Guagliardo, and J. G. Joseph. "Inpatient Childhood Asthma Treatment: Relationship of Hospital Characteristics to Length of Stay and Cost: Analyses of New York State Discharge Data, 1995." Archives of Pediatric and Adolescent Medicine 156, no. 1 (2002): 67-72.

Kessler, Daniel P., and Mark B. McClellan. "The Effects of Hospital Ownership on Medical Productivity." RAND Journal of Economics 33, no. 3 (2002): 488-506.

Koop, Gary, Jacek Osiewalski, and Mark F. J. Steel. "Bayesian Efficiency Analysis through Individual Effects: Hospital Cost Frontiers." Journal of Econometrics 76, no. 1-2 (1997): 77-105.

Lawrence, Carol M. "The Effect of Ownership Structure and Accounting System Type on Hospital Costs." Research in governmental and nonprofit accounting. 6, (1990): 35-60.

Li, T., and R. Rosenman. "Cost Inefficiency in Washington Hospitals: A Stochastic Frontier Approach using Panel Data." Health Care Management Science 4, no. 2 (2001): 73-81.

Mark, T. L. "Analysis of the Rationale for, and Consequences of, Nonprofit and for-Profit Ownership Conversions." Health Services Research 34, no. 1 Part 1 (1999): 83-101.

McCue, M. J., and D. Burroughs. "A Trend Analysis of Financial Accounts. from TEFRA to PPS 7." Hosp Top 71, no. 4 (1993): 17-26. 
Menke, T. J. "The Effect of Chain Membership on Hospital Costs." Health Services Research 32, no. 2 (1997): 177-196.

Molinari, C., L. Morlock, J. Alexander, and C. A. Lyles. "Hospital Board Effectiveness: Relationships between Governing Board Composition and Hospital Financial Viability." Health Services Research 28, no. 3 (1993): 358-377.

Ozcan, Y. A., R. D. Luke, and C. Haksever. "Ownership and Organizational Performance. A Comparison of Technical Efficiency Across Hospital Types." Medical Care 30, no. 9 (1992): 781-794.

Picone, G., S. Y. Chou, and F. Sloan. "Are for-Profit Hospital Conversions Harmful to Patients and to Medicare?" Rand Journal of Economics 33, no. 3 (2002): 507-523.

Potter, S. J. "A Longitudinal Analysis of the Distinction between for-Profit and Not-for-Profit Hospitals in America." Journal of Health and Social Behavior 42, no. 1 (2001): 17-44.

Rosko, M. D. "Cost Efficiency of US Hospitals: A Stochastic Frontier Approach." Health Economics 10, no. 6 (2001b): 539-551.

Rosko, M. D. "Impact of HMO Penetration and Other Environmental Factors on Hospital XInefficiency." Medical Care Research Review 58, no. 4 (2001a): 430-454.

Rosko, M. D. "Impact of Internal and External Environmental Pressures on Hospital Inefficiency." Health Care Management Science 2, no. 2 (1999): 63-74.

Sari, Nazmi. "Efficiency Outcomes of Market Concentration and Managed Care." International Journal of Industrial Organization 21, no. 10 (2003): 1571-1589.

Shen, Yu-Chu. "Changes in Hospital Performance After Ownership Conversions." Inquiry 40, no. 3 (2003): 217-234.

Shukla, R. K., J. Pestian, and J. Clement. "A Comparative Analysis of Revenue and Cost-Management Strategies of Not-for-Profit and for-Profit Hospitals." Hospital Health Services Administration 42, no. 1 (1997): 117-134.

Sloan, Frank A., Picone GA, Taylor DH Jr, and Chou S. "Does Where You Are Admitted Make A Difference? An Analysis of Medicare Data." In Frontiers in Health Policy Research Volume 2, A.M. Garber, ed. (1999): 1-25.

Vitaliano, Donald F., and Mark Toren. "Hospital Cost and Efficiency in a Regime of Stringent Regulation." Eastern Economic Journal 22, no. 2 (1996): 161-175.

Wang, B. B., T. T. Wan, J. Clement, and J. Begun. "Managed Care, Vertical Integration Strategies and Hospital Performance." Health Care Management Science 4, no. 3 (2001): 181-191.

Wilcox-Gok, Virginia. "The Effects of for-Profit Status and System Membership on the Financial Performance of Hospitals." Applied Economics 34, no. 4 (2002): 479-489. 
Younis, M., J. Rice, and J. Barkoulas. "An Empirical Investigation of Hospital Profitability in the PostPPS Era." Journal of Health Care Finance 28, no. 2 (2001): 65-73.

Zeckhauser, Richard, Jayendu Patel, and Jack Needleman. The Economic Behavior of for-Profit and Nonprofit Hospitals: The Impact of Ownership on Responses to Changing Reimbursement and Market Environments. Cambridge, Massachusetts: Harvard University, 1995.

Zuckerman, Stephen, Jack Hadley, and Lisa Iezzoni. "Measuring Hospital Efficiency with Frontier Cost Functions." Journal of Health Economics 13, no. 3 (1994): 255-280.

\section{Other References}

Arrow, Kenneth J. "Uncertainty and the Welfare Economics of Medical Care." American Economic Review (1963): 941-973.

Ben-Ner, Avner, and Benedetto Gui. The Nonprofit Sector in the Mixed Economy. Ann Arbor: University of Michigan Press, 1993.

Card, David, and Alan B. Krueger. "Time-Series Minimum-Wage Studies: A Meta-Analysis." American Economic Review 85, no. 2 (1995): 238-243.

Carey, K. "Hospital Cost Efficiency and System Membership." Inquiry 40, no. 1 (2003): 25-38.

Cohen J. Statistical power analysis for the behavioral sciences. New York: Academic Press; 1977.

David, Guy. "The Convergence Between Nonprofit and For-Profit Hospitals in the United States." Ph.D. Dissertation, University of Chicago, 2004.

Devereaux, P. J., P. T. Choi, C. Lacchetti, B. Weaver, H. J. Schunemann, T. Haines, J. N. Lavis, B. J. Grant, D. R. Haslam, M. Bhandari, T. Sullivan, D. J. Cook, S. D. Walter, M. Meade, H. Khan, N. Bhatnagar, and G. H. Guyatt. "A Systematic Review and Meta-Analysis of Studies Comparing Mortality Rates of Private for-Profit and Private Not-for-Profit Hospitals." CMAJ Canadian Medical Association Journal 166, no. 11 (2002): 1399-1406.

Devereaux, P. J., D. Heels-Ansdell, C. Lacchetti, T. Haines, K. E. Burns, D. J. Cook, N. Ravindran, S. D. Walter, H. McDonald, S. B. Stone, R. Patel, M. Bhandari, H. J. Schunemann, P. T. Choi, A. M. Bayoumi, J. N. Lavis, T. Sullivan, G. Stoddart, and G. H. Guyatt. "Payments for Care at Private forProfit and Private Not-for-Profit Hospitals: A Systematic Review and Meta-Analysis." CMAJ Canadian Medical Association Journal 170, no. 12 (2004): 1817-1824.

Djankov, Simeon, and Peter Murrell. "Enterprise Restructuring in Transition: A Quantitative Survey." Journal of Economic Literature 40, no. 3 (2002): 739-792.

Duggan, Mark. "Hospital Market Structure and the Behavior of Not-for-Profit Hospitals." RAND Journal of Economics 33, no. 3 (2002): 433-446. 
Frank, Richard G., and David S. Salkever. "The Supply of Charity Services by Nonprofit Hospitals: Motives and Market Structure." RAND Journal of Economics 22, no. 3 (1991): 430-445.

Glaeser, Edward L., and Andrei Shleifer. "Not-for-Profit Entrepreneurs." Journal of Public Economics 81, no. 1 (2001): 99-115.

Grossman, S., and O. Hart. "The Costs and Benefits of Ownership: A Theory of Vertical and Lateral Integration." Journal of Political Economy 98, (1986): 1119-1158.

Hansmann, Henry B. "The Role of Nonprofit Enterprise." Yale Law Journal 89, no. 5 (1980): 835-901.

Hart, Oliver. Firms, Contracts, and Financial Structure. Oxford and New York: Oxford University Press, Clarendon Press, 1995.

Hart, Oliver, Andrei Shleifer, and Robert W. Vishny. "The Proper Scope of Government: Theory and an Application to Prisons." Quarterly Journal of Economics 112, no. 4 (1997): 1127-1161.

Hedges, Larry V. and Ingram Olkin. Statistical Methods for Meta-Analysis. Orlando, FL: Academic Press, Inc. 1985.

Kornai, János. "The Softness of the Budget Constraint.” Kyklos 39 (1986): 3-30.

Kornai, János, Eric Maskin, and Gerard Roland, "Understanding the Soft Budget Constraint," Journal of Economic Literature XLI(4) (2003): 1095-1136.

Laffont, Jean-Jacques, and Jean Tirole. "Chapter 17 " In A Theory of Incentives in Procurement and Regulation. Cambridge, MA: MIT Press, 1993, 637-659.

Lakdawalla, Darius, and Tomas Philipson. "Nonprofit Production and Competition." National Bureau of Economic Research Working Paper 6377, 1998.

Lau, Joseph, John PA Ioannidis, Christopher H Schmid. "Summing up evidence: one answer is not always enough.” Lancet. 351 (1998), 123-127.

Malani, Anup, Tomas Philipson, and Guy David. "Theories of Firm Behavior in the Nonprofit Sector: A Synthesis and Empirical Evaluation." In The Governance of Not-for-Profit Organizations. Edited by Edward L. Glaeser ed. NBER Conference Report series. Chicago and London: University of Chicago Press, 2003, 181-215.

McClellan, Mark, and Douglas Staiger. "Comparing Hospital Quality at for-Profit and Not-for-Profit Hospitals." In The Changing Hospital Industry: Comparing Not-for-Profit and for-Profit Institutions. Edited by David M. Cutler ed. NBER Conference Report series. Chicago and London: University of Chicago Press, 2000, 93-112.

Needleman, Jack. "The Role of Nonprofits in Health Care." Journal of Health Politics, Policy and Law 26, no. 5 (2001): 1113-1130.

Newhouse, Joseph P. "Toward a Theory of Nonprofit Institutions: An Economic Model of a Hospital." American Economic Review 60, (1970): 64-74. 
Pauly, Mark V., and Michael Redisch. "The Not-for-Profit Hospital as a Physicians' Cooperative." American Economic Review 63, no. 1 (1973): 87-99.

Rosenthal, R. Meta-Analytic Procedures for Social Research. Revised Edition. Revised Edition ed. Newbury Park, CA: Sage Publications, 1991.

Rosenthal, R. and D. Rubin. A simple, general purpose display of magnitude of experimental effect. Journal of Educational Psychology, 74 (1982), 166-169.

Sloan, Frank A. "Hospital Ownership and Cost and Quality of Care: Is there a Dime's Worth of Difference?" Journal of Health Economics 20, no. 1 (2001): 1-21.

Sloan, Frank A. "Not-for-Profit Ownership and Hospital Behavior." Handbook of Health Economics. 1B, (2000): 1141-1174.

Stanley, T. D. "Wheat from Chaff: Meta-Analysis as Quantitative Literature Review." Journal of Economic Perspectives 15, no. 3 (2001): 131-150.

Stanley, T. D., and Stephen B. Jarrell. "Gender Wage Discrimination Bias? A Meta-Regression Analysis." Journal of Human Resources 33, no. 4 (1998): 947-973.

Vickers, John, and George Yarrow. Privatization: An Economic Analysis. Cambridge and London: MIT Press, 1988.

Weisbrod, Burton A. The Nonprofit Economy. and London: Harvard University Press, 1988. 


\section{Appendix. Technical Details on the Effect Sizes}

The precision of the effect size. In order to answer the second question, how precise is the effect size, we need to compute the confidence interval around the effect size. The adjusted effect size, $Z_{r}$, is distributed normally, with variance that is proportional to the inverse of sample size. Specifically,

$$
\operatorname{variance}\left(Z_{r}\right)=\frac{1}{n-3}
$$

Then for each study, we can compute the $95 \%$ confidence interval around the adjusted effect size as follows:

$$
Z_{r} \pm 1.96 * \frac{1}{\sqrt{n-3}}
$$


Figure 1. US Community Hospital Beds (in thousands), total and by ownership, 1928-2000

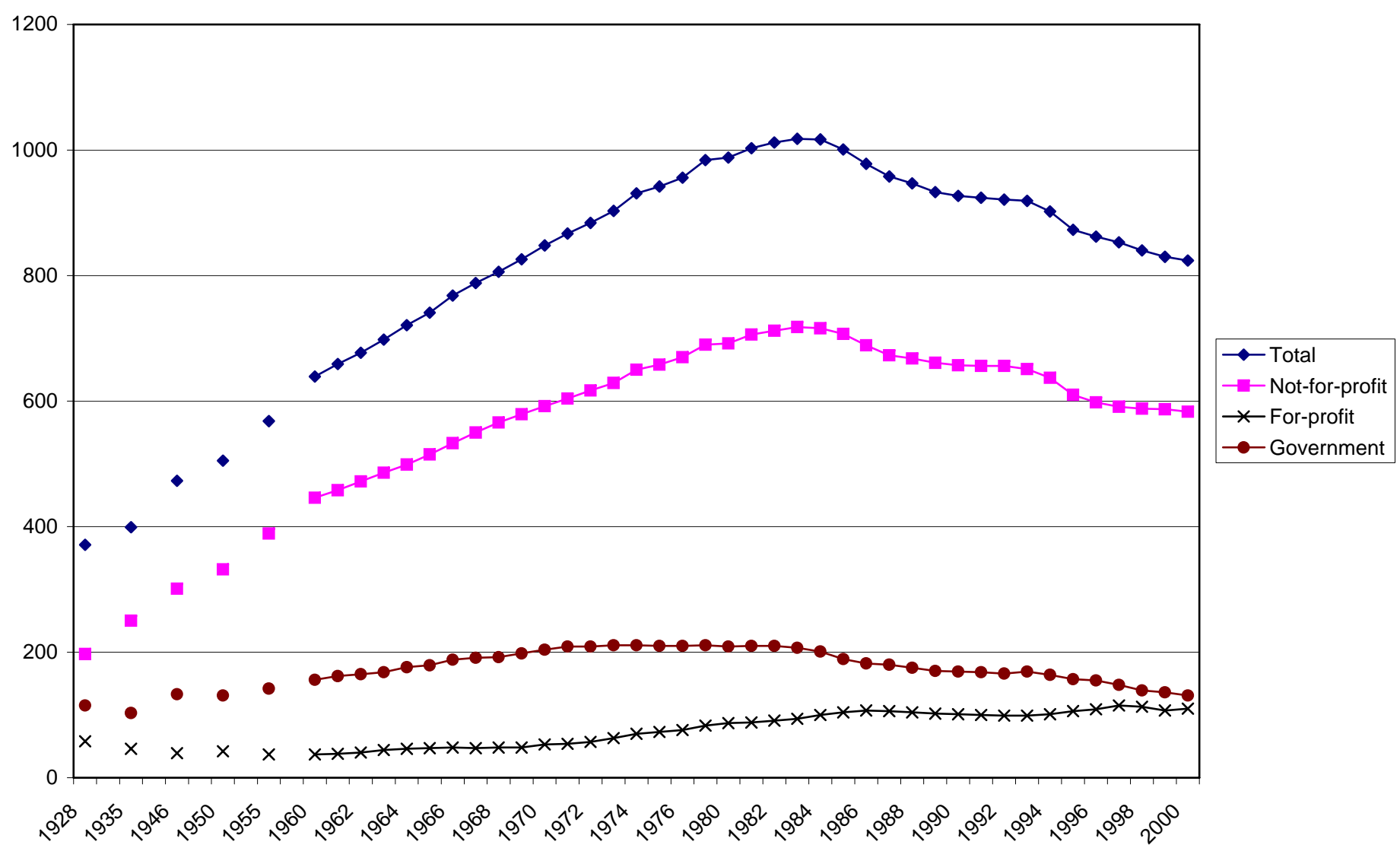

Source: Eggleston (2005), based on Rorem (1930); Hayes (1954); American Hospital Association Hospital Statistics (various years). 


\section{Figure 2. Flowchart of Literature Search Results}

Potentially relevant studies from 1990 to 2004 that were identified and screened for retrieval through Medline, Econlit, Proquest, ABI, and through contacting all corresponding authors of initially included studies $(n=1434)$

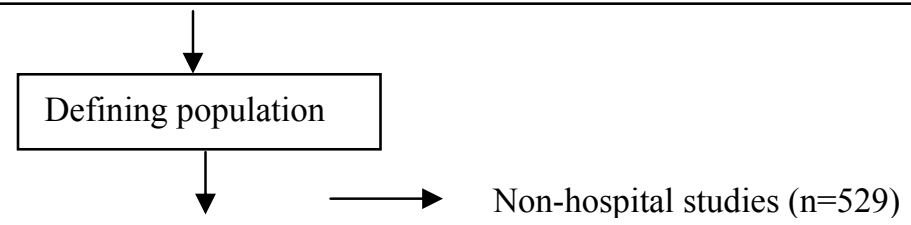

Hospital studies $(\mathrm{n}=905)$

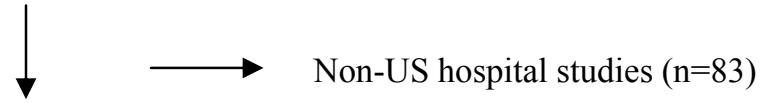

US hospital studies $(\mathrm{n}=822)$

$\downarrow \quad \longrightarrow \quad$ Non-acute general short stay hospital studies $(\mathrm{n}=36)$

Acute general short stay hospital studies

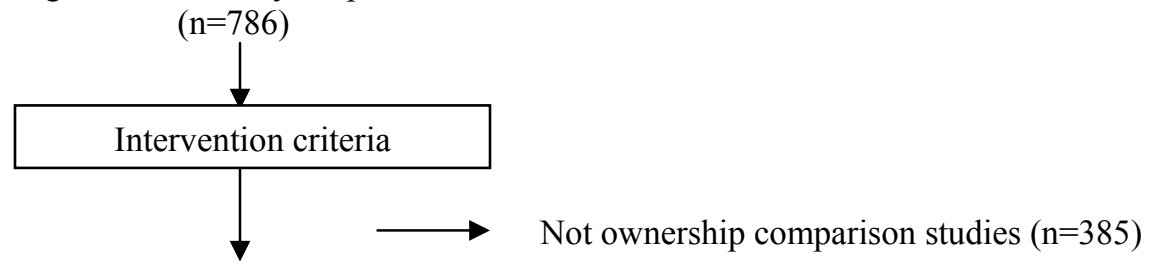

Ownership comparison studies $(n=401)$

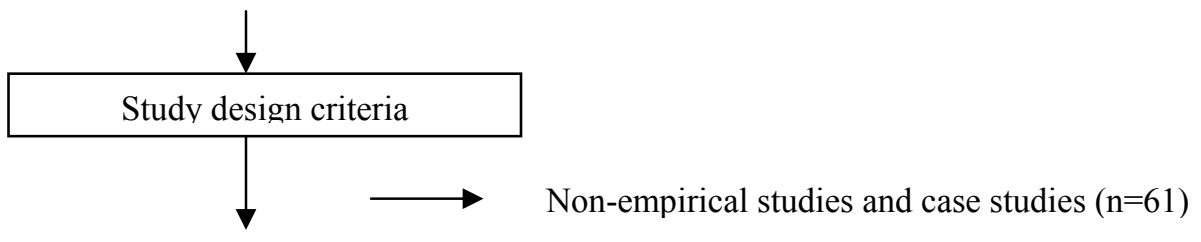

Empirical studies $(\mathrm{n}=340)$

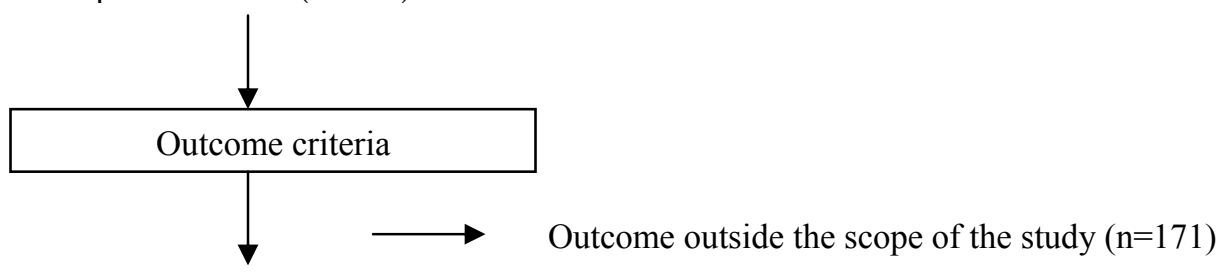

Studies within the outcome scope $(n=169)$

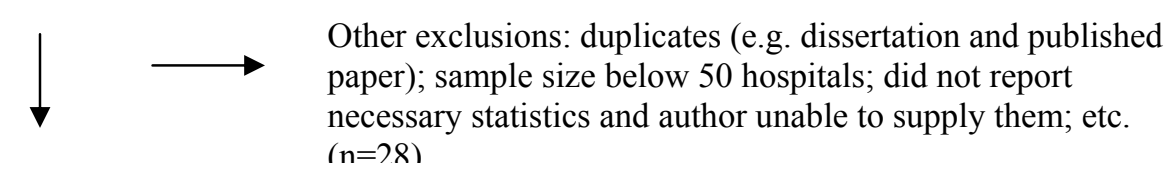

141 empirical studies fit the selection criteria. 
Figure 3. Summary of Effect Sizes For Hospital Cost 3A. Comparison between Not-For-Profit and For-Profit Hospitals

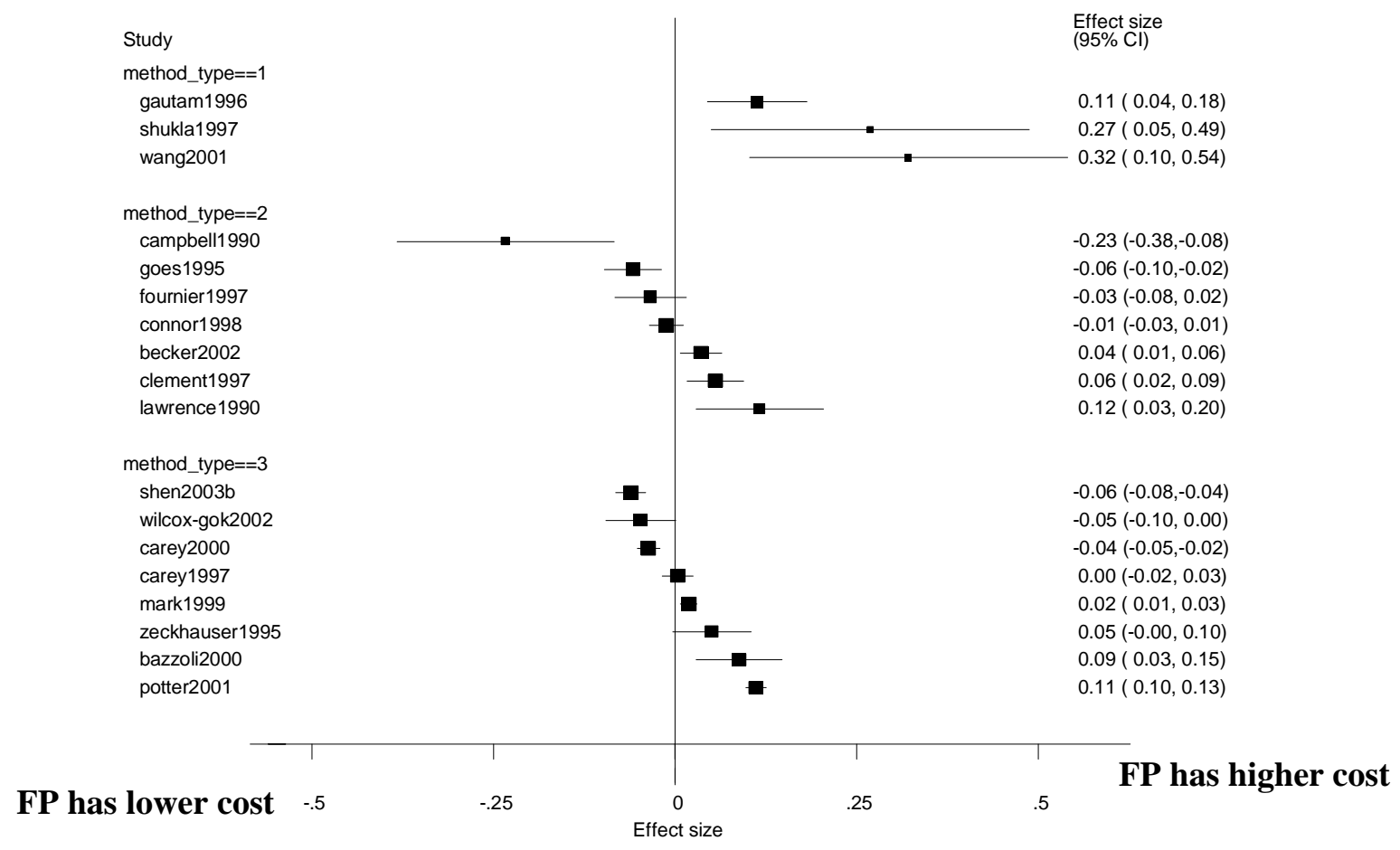

\section{B. Comparison between Not-For-Profit and Government Hospitals}

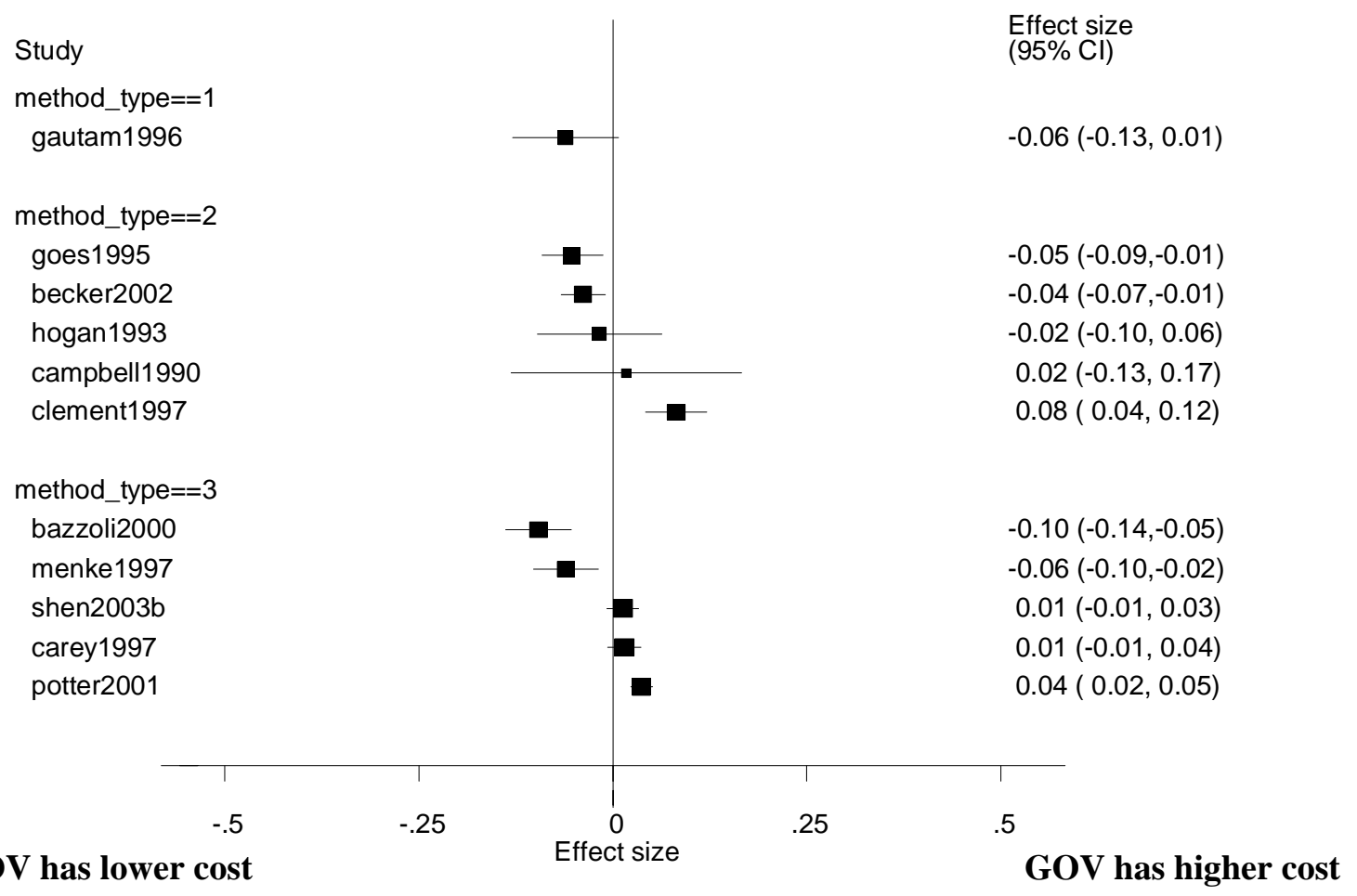


Figure 4. Summary of Effect Sizes For Hospital Revenue 4A. Comparison between Not-For-Profit and For-Profit Hospitals

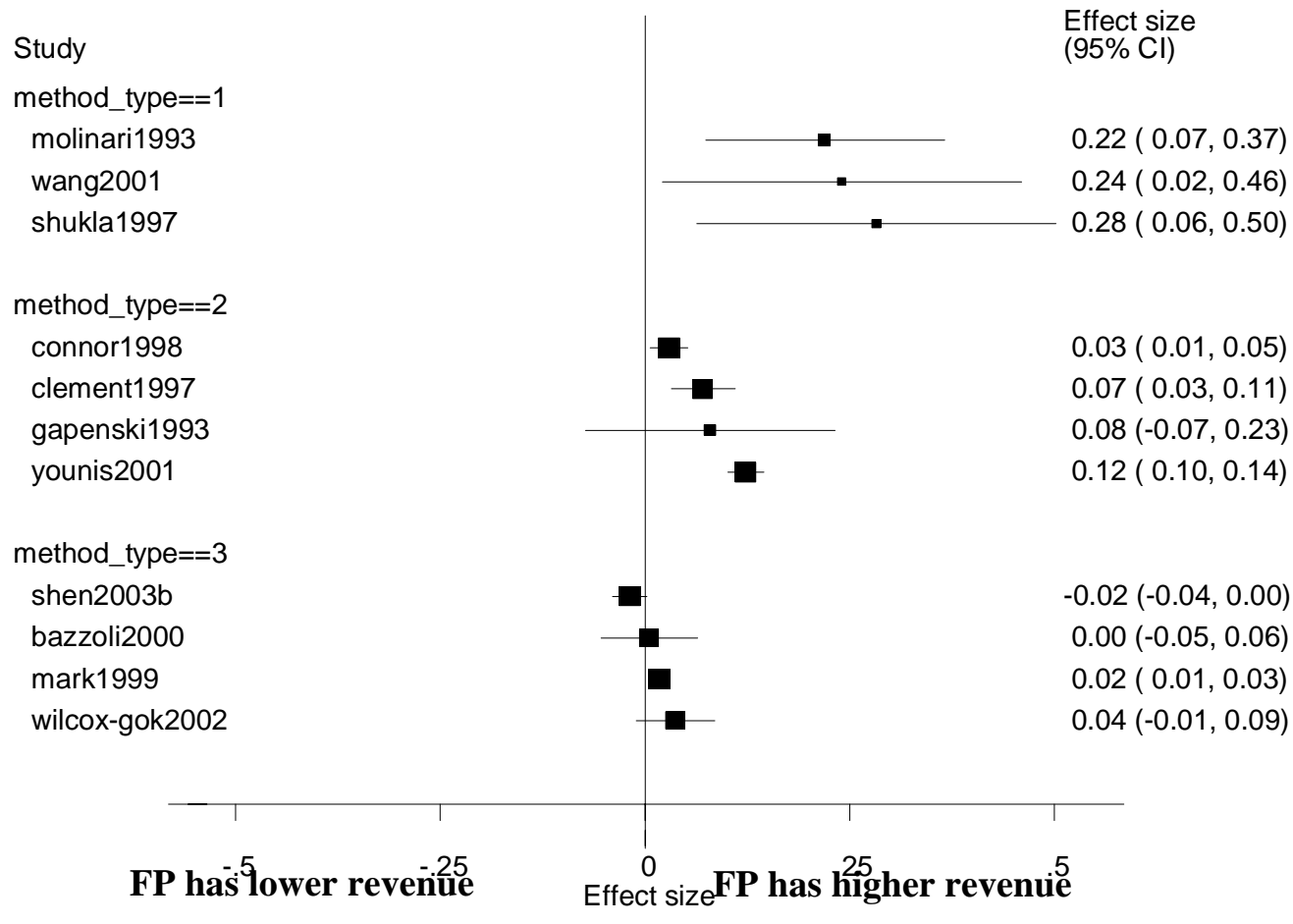

\section{B. Comparison between Not-For-Profit and Government Hospitals}

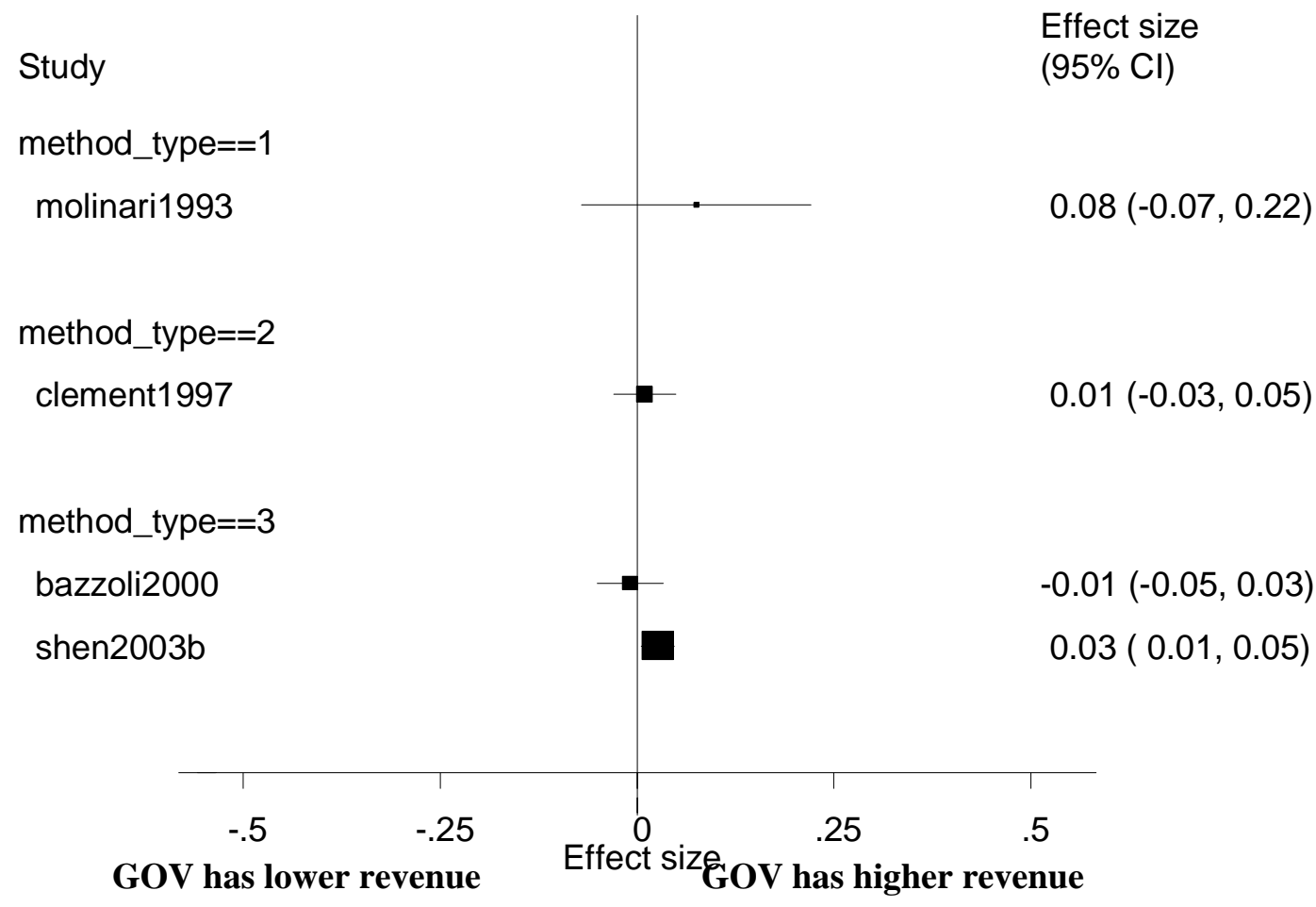


Figure 5. Summary of Effect Sizes For Profit Margins 5A. Comparison between Not-For-Profit and For-Profit Hospitals

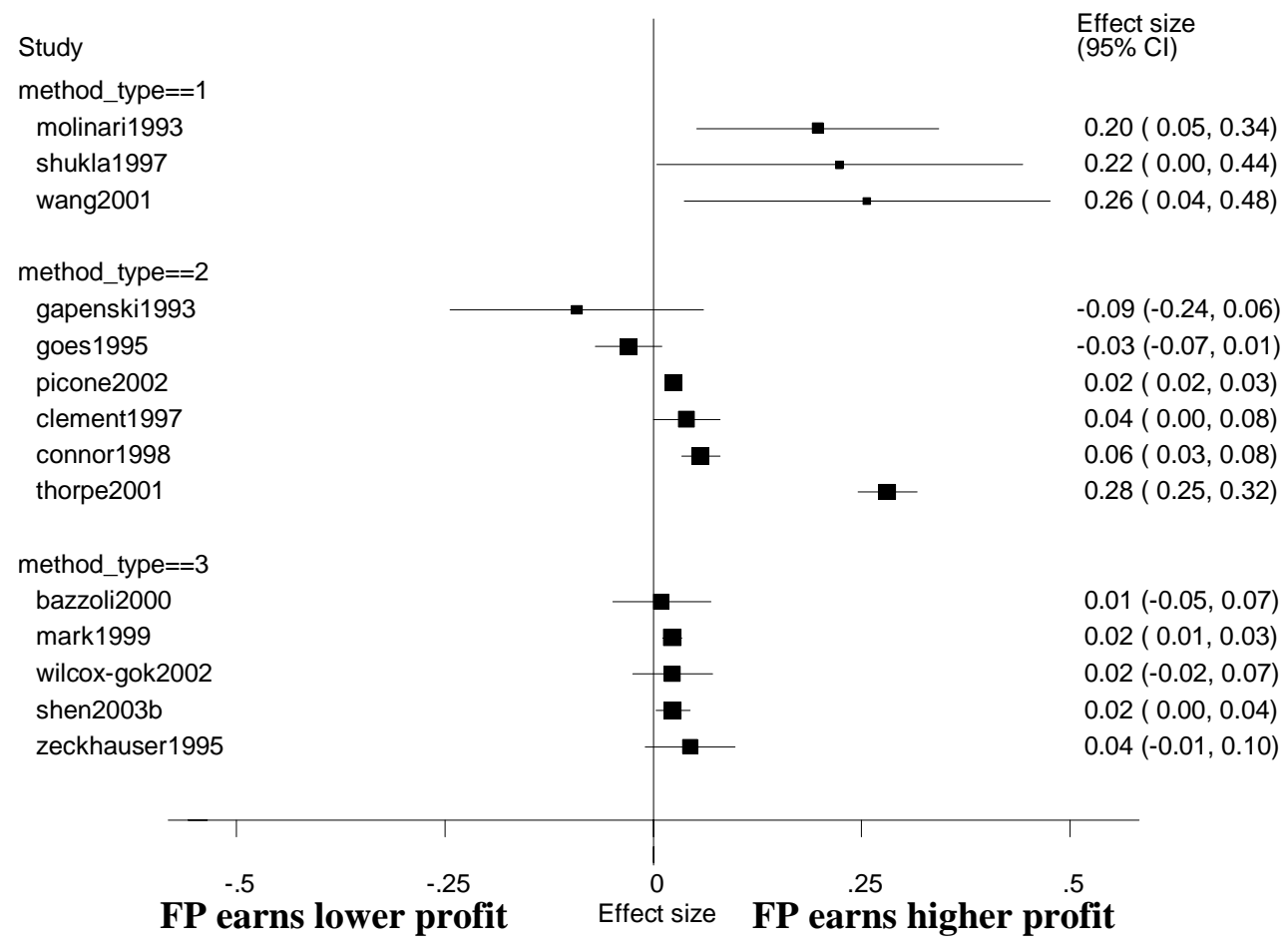

5B. Comparison between Not-For-Profit and Government Hospitals

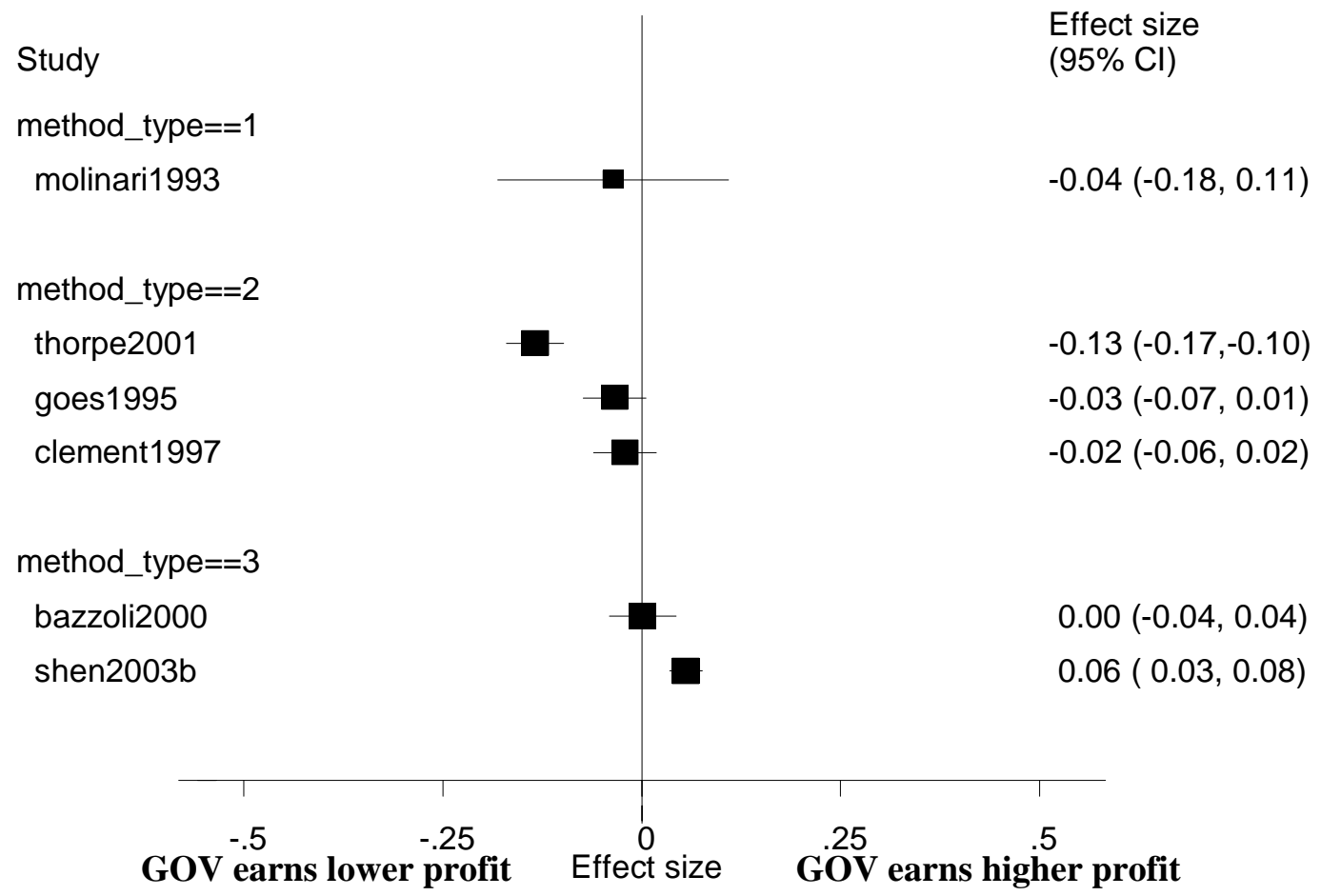




\section{Figure 6. Summary of Effect Sizes For Efficiency 6A. Comparison between Not-For-Profit and For-Profit Hospitals}

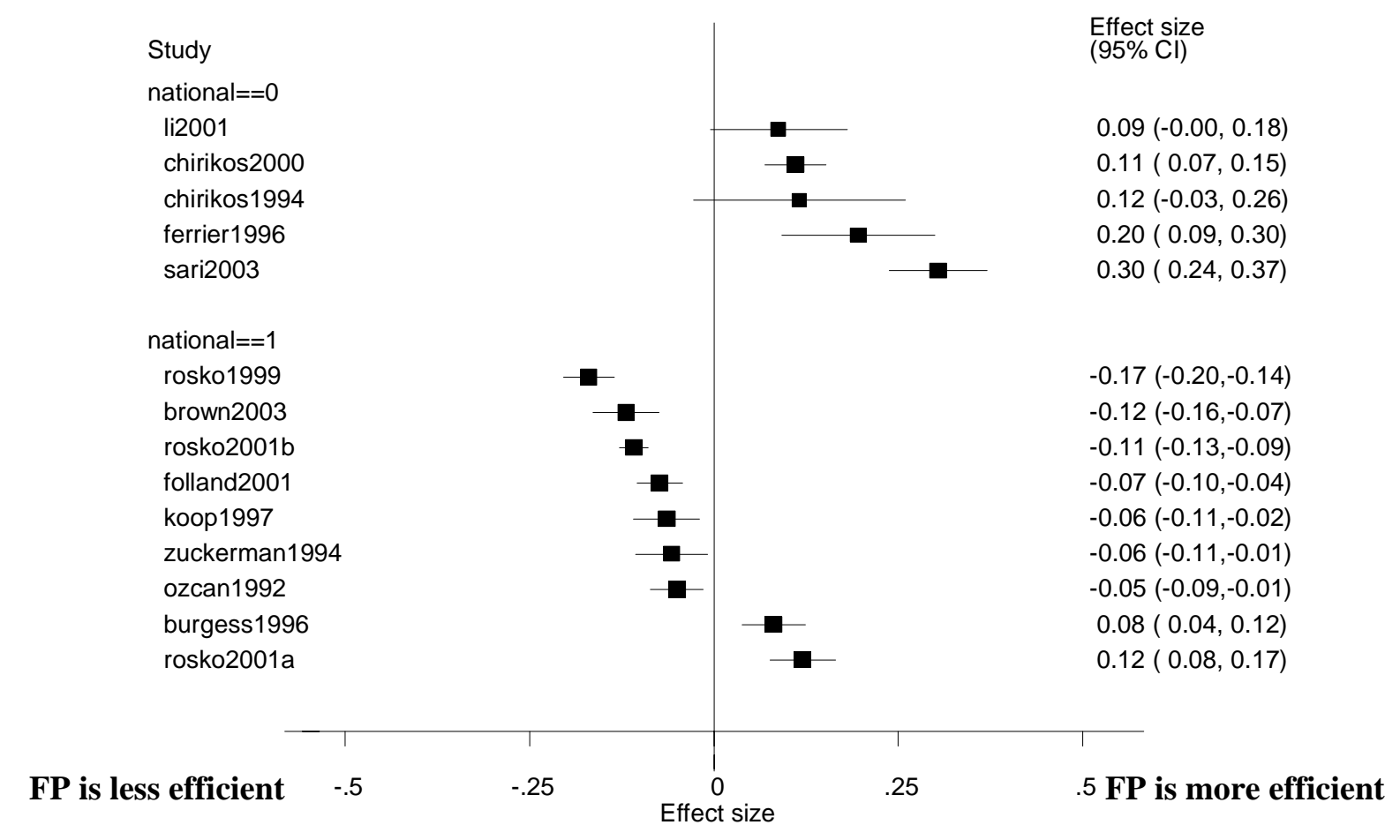

\section{B. Comparison between Not-For-Profit and Government Hospitals}

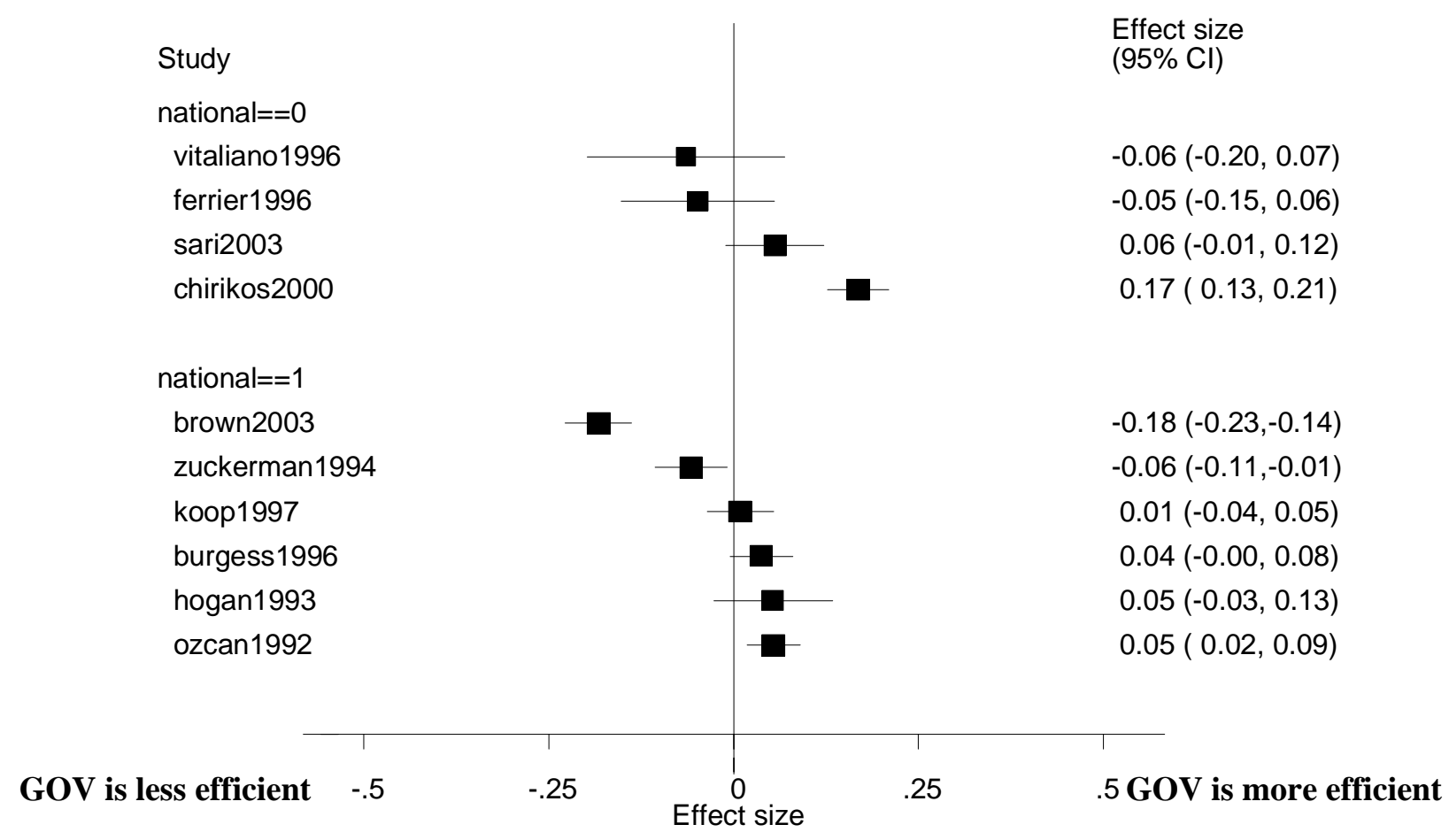


Figure 7. Relationship Between T-Stat and Degrees of Freedom

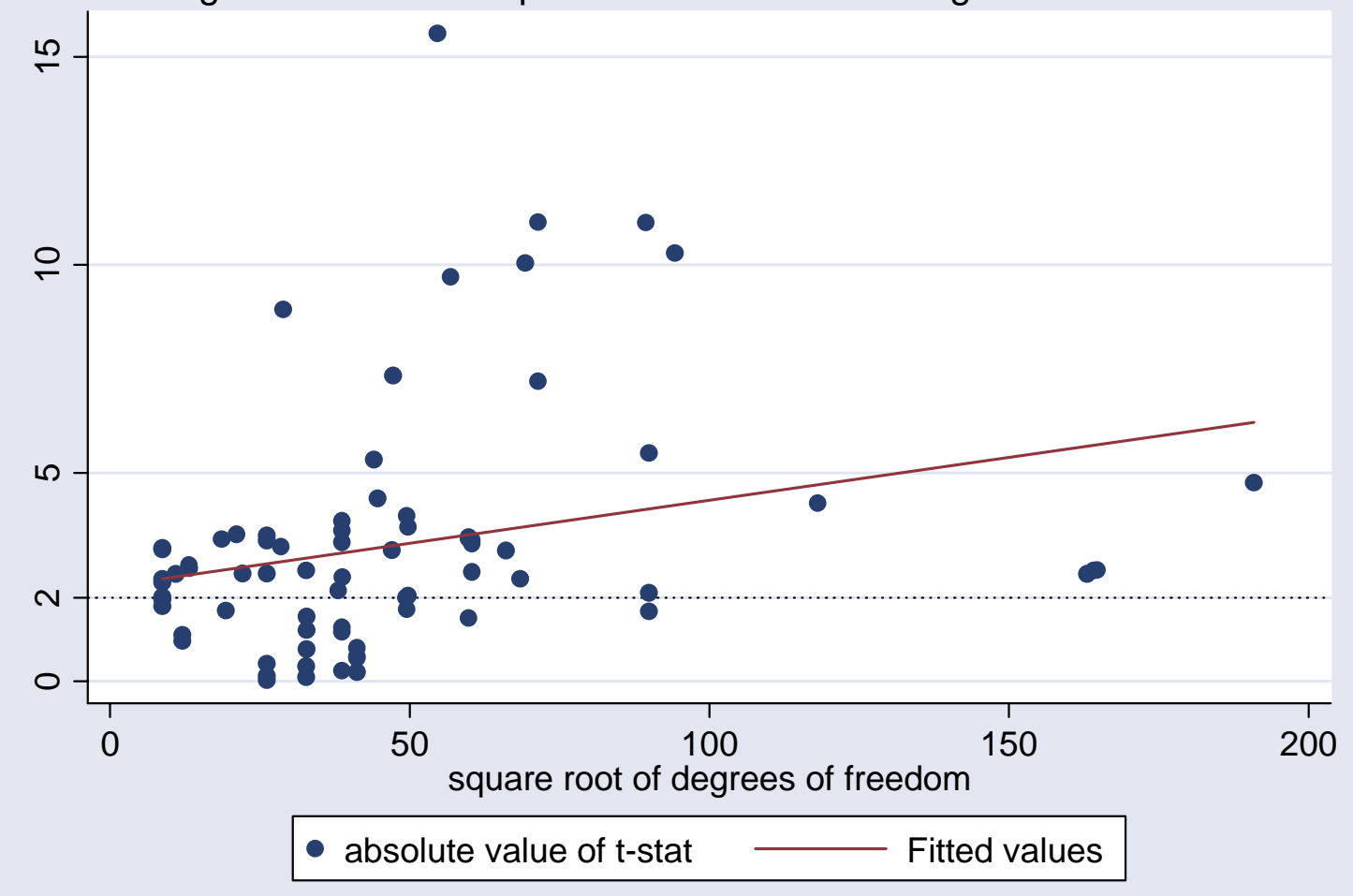


Table 1. Summary of Included Studies ${ }^{*}$

\begin{tabular}{|c|c|c|c|c|c|c|c|c|}
\hline article ID & Cost & Revenue & \begin{tabular}{|l} 
Profit \\
Margin
\end{tabular} & Efficiency & Covered region & Covered years & \begin{tabular}{|l|} 
Total \\
sample size
\end{tabular} & $\begin{array}{l}\text { Type of } \\
\text { ownership } \\
\text { studied }\end{array}$ \\
\hline bazzoli2000 & $\mathrm{X}$ & $\mathrm{X}$ & $\mathrm{X}$ & & US & 1995 & 1112 & $N, F, G$ \\
\hline becker2002 & $x$ & & & & US & 1994 & 4705 & $N, F, G$ \\
\hline brown2003 & & & & $x$ & MSA & 1992-1996 & 1907 & $N, F, G$ \\
\hline burgess1996 & & & & $x$ & US & 1988 & 2112 & $N, F, G$ \\
\hline campbell1990 & $x$ & & & & FL & 1986 & 176 & $N, F, G$ \\
\hline carey1997 & $x$ & & & & US & 1987-1991 & 8665 & $N, F, G$ \\
\hline carey2000 & $x$ & & & & US & 1987-1992 & 16752 & $N, F$ \\
\hline chirikos1994 & & & & $x$ & $F L$ & 1989 & 189 & $\mathrm{~N}, \mathrm{~F}$ \\
\hline chirikos2000 & & & & $x$ & FL & 1982-1993 & 2232 & $N, F, G$ \\
\hline clement1997 & $x$ & $x$ & $x$ & & MSA & 1995 & 2462 & $N, F, G$ \\
\hline connor1998 & $\mathrm{X}$ & $X$ & $x$ & & US & 1994 & 3617 & $\mathrm{~N}, \mathrm{~F}$ \\
\hline ferrier1996 & & & & $x$ & AK, LA, OK, TX & 1989 & 360 & $N, F, G$ \\
\hline folland2001 & & & & $x$ & US & 1985 & 2007 & $N, F$ \\
\hline fournier1997 & $x$ & & & & $F L$ & 1984-1986 & 534 & $N, F, G$ \\
\hline gapenski1993 & & $x$ & $x$ & & FL & 1989 & 169 & $\mathrm{~N}, \mathrm{~F}$ \\
\hline gautam1996 & $x$ & & & & MSA & 1990-1992 & 825 & $N, F, G$ \\
\hline goes1995 & $x$ & & $x$ & & CA & 1981-1990 & 3232 & $N, F, G$ \\
\hline hogan1993 & $x$ & & & $x$ & US & 1983-1984 & 600 & $N F, G$ \\
\hline koop1997 & & & & $X$ & US & 1987-1991 & 1910 & $N, F, G$ \\
\hline lawrence1990 & $x$ & & & & US & 1986 & 499 & $N, F$ \\
\hline li2001 & & & & $x$ & WA & 1988-1993 & 450 & $\mathrm{~N}, \mathrm{~F}$ \\
\hline mark1999 & $x$ & $x$ & $x$ & & Us & 1987-1995 & 30459 & $N, F^{*}$ \\
\hline menke1997 & $x$ & & & & Us & 1995 & 2200 & $N, G$ \\
\hline molinari1993 & & $x$ & $X$ & & CA & 1985 & 186 & $N, F$ \\
\hline ozcan1992 & & & & $x$ & MSA & 1987 & 3000 & $N, F, G$ \\
\hline picone2002 & & & $x$ & & US & 1985-1995 & 40095 & $N, F, G^{*}$ \\
\hline potter2001 & $x$ & & & & us & 1980, 1985, 1990, 1994 & 19453 & $N, F, G$ \\
\hline rosko1999 & & & & $x$ & US & 1994 & 3262 & $\mathrm{~N}, \mathrm{~F}$ \\
\hline rosko2001a & & & & $x$ & MSA & 1997 & 1966 & $N, F$ \\
\hline rosko2001b & & & & $x$ & MSA & 1990-1996 & 10388 & $\mathrm{~N}, \mathrm{~F}$ \\
\hline sari2003 & & & & $x$ & FL & 1990-1997 & 876 & $N, F, G$ \\
\hline shen2003b & $x$ & $x$ & $x$ & & US & 1987-1998 & 8915 & $N, F, G^{*}$ \\
\hline shukla1997 & $x$ & $x$ & $x$ & & VA & 1993 & 83 & $N, F$ \\
\hline thorpe2001 & & & $x$ & & MSA & 1991-1997 & 21000 & $N, F, G$ \\
\hline vitaliano1996 & & & & $x$ & NY & 1991 & 219 & $N, G$ \\
\hline wang2001 & $x$ & $x$ & $x$ & & VA & 1993 & 83 & $N, F$ \\
\hline wilcox-gok2002 & $\mathrm{X}$ & $\mathrm{X}$ & $X$ & & FL & 1984-1987 & 1666 & $\mathrm{~N}, \mathrm{~F}$ \\
\hline younis2001 & & $x$ & & & US & 1991, 1995 & 8019 & $\mathrm{~N}, \mathrm{~F}$ \\
\hline zeckhauser1995 & $x$ & & $x$ & & CA, FL & 1982, 1984, 1986, 1988, 1990 & 11075 & $\mathrm{~N}, \mathrm{~F}$ \\
\hline zuckerman1994 & & & & $x$ & US & 1987 & 1600 & $N, F, G$ \\
\hline Total & 20 & 11 & 14 & 16 & & & & \\
\hline
\end{tabular}

$¥$ The following additional studies are included in the sensitivity analysis: Ettner et al. (2001), Huang et al. (2002), Kessler and McClellan (2002), Sloan et al. (1999), and Bazzoli et al (2004). The complete bibliography information is listed in the reference section.

MSA=Metropolitan Statistical Areas (Urban)

* Studies of ownership conversions 
Table 2. Share of Studies With A Given Study Feature

\begin{tabular}{|c|c|c|c|c|}
\hline Study Features & Cost & Revenue & Profit & Efficiency \\
\hline \multicolumn{5}{|c|}{ Not-For-Profit and For-Profit Comparison Studies } \\
\hline \multicolumn{5}{|l|}{\begin{tabular}{|l|} 
Methodology classification \\
\end{tabular}} \\
\hline Type I & $17 \%$ & $27 \%$ & $21 \%$ & $21 \%$ \\
\hline Type II & $39 \%$ & $36 \%$ & $43 \%$ & $57 \%$ \\
\hline Type III & $44 \%$ & $36 \%$ & $36 \%$ & $21 \%$ \\
\hline \multicolumn{5}{|l|}{ Emphasis on ownership } \\
\hline Ownership is the research focus & $50 \%$ & $55 \%$ & $50 \%$ & $64 \%$ \\
\hline $\begin{array}{l}\text { Ownership included as a control variable } \\
\text { Functional form }\end{array}$ & $50 \%$ & $45 \%$ & $50 \%$ & $36 \%$ \\
\hline Dependent variable is not log transformed & $39 \%$ & $73 \%$ & & \\
\hline Dependent variable is log transformed & $61 \%$ & $27 \%$ & & \\
\hline \multicolumn{5}{|l|}{ Efficiency study model assumption } \\
\hline Assumes a stochastic frontier model & & & & $\begin{array}{l}68 \% \\
32 \%\end{array}$ \\
\hline \multicolumn{5}{|l|}{ Covered region } \\
\hline National or other state sample & $61 \%$ & $55 \%$ & $50 \%$ & $79 \%$ \\
\hline Virginia & $11 \%$ & $18 \%$ & $14 \%$ & $0 \%$ \\
\hline California & $8 \%$ & $9 \%$ & $18 \%$ & $0 \%$ \\
\hline Florida & $19 \%$ & $18 \%$ & $18 \%$ & $21 \%$ \\
\hline \multicolumn{5}{|l|}{ Data type } \\
\hline Administrative data only & $33 \%$ & $55 \%$ & $36 \%$ & $21 \%$ \\
\hline Survey data only & $44 \%$ & $45 \%$ & $57 \%$ & $50 \%$ \\
\hline Use both administrative and survey data & $22 \%$ & $0 \%$ & $7 \%$ & $29 \%$ \\
\hline Number of studies & 18 & 11 & 14 & 14 \\
\hline \multicolumn{5}{|c|}{ Not-For-Profit and Government Comparison Studies } \\
\hline \multicolumn{5}{|l|}{ Methodology classification } \\
\hline Type I & $9 \%$ & $25 \%$ & $17 \%$ & $10 \%$ \\
\hline Type II & $45 \%$ & $25 \%$ & $50 \%$ & $80 \%$ \\
\hline Type III & $45 \%$ & $50 \%$ & $33 \%$ & $10 \%$ \\
\hline \multicolumn{5}{|l|}{ Emphasis on ownership } \\
\hline Ownership is the research focus & $18 \%$ & $25 \%$ & $17 \%$ & $50 \%$ \\
\hline $\begin{array}{l}\text { Ownership included as a control variable } \\
\text { Functional form }\end{array}$ & $82 \%$ & $75 \%$ & $83 \%$ & $50 \%$ \\
\hline Dependent variable is not log transformed & $36 \%$ & $50 \%$ & & \\
\hline Dependent variable is log transformed & $55 \%$ & $50 \%$ & & \\
\hline \multicolumn{5}{|l|}{ Efficiency study model assumption } \\
\hline $\begin{array}{l}\text { Assumes a stochastic frontier model } \\
\text { Assumes a deterministic model (DEA) }\end{array}$ & & & & $\begin{array}{l}55 \% \\
45 \%\end{array}$ \\
\hline \multicolumn{5}{|l|}{ Covered region } \\
\hline National or other state sample & $82 \%$ & $75 \%$ & $67 \%$ & $80 \%$ \\
\hline Virginia & $0 \%$ & $0 \%$ & $0 \%$ & $0 \%$ \\
\hline California & $9 \%$ & $25 \%$ & $33 \%$ & $0 \%$ \\
\hline Florida & $9 \%$ & $0 \%$ & $0 \%$ & $20 \%$ \\
\hline \multicolumn{5}{|l|}{ Data type } \\
\hline Administrative data only & $18 \%$ & $25 \%$ & $17 \%$ & $20 \%$ \\
\hline Survey data only & $36 \%$ & $75 \%$ & $67 \%$ & $30 \%$ \\
\hline Use both administrative and survey data & $45 \%$ & $0 \%$ & $17 \%$ & $50 \%$ \\
\hline Number of studies & 11 & 4 & 6 & 10 \\
\hline
\end{tabular}


Table 3. Random-Effects Meta Regression: Comparison Between Not-For-Profit and For-Profit Hospitals

\begin{tabular}{|c|c|c|c|c|c|c|c|c|}
\hline \multirow[b]{2}{*}{ Study Features } & \multicolumn{8}{|c|}{ Dependent Variable is the Standardized Effect Size } \\
\hline & \multicolumn{2}{|c|}{ Cost } & \multicolumn{2}{|c|}{ Revenue } & \multicolumn{2}{|c|}{ Profit Margin } & \multicolumn{2}{|c|}{ Efficiency } \\
\hline & Coef. & SE & Coef. & SE & Coef. & SE & Coef. & SE \\
\hline Methodology classification & & & & & & & & \\
\hline Type I (reference group) & $0.21 * *$ & 0.06 & $0.28^{* *}$ & 0.05 & 0.19 ** & 0.08 & 0.00 & 0.06 \\
\hline Type II & $-0.20^{* *}$ & 0.07 & $-0.18 * *$ & 0.05 & -0.16 ** & 0.08 & -0.04 & 0.07 \\
\hline Type III & $-0.17^{\star *}$ & 0.06 & $-0.26 * *$ & 0.06 & $-0.16 *$ & 0.08 & -0.04 & 0.09 \\
\hline Ownership included as a control variable & -0.03 & 0.03 & $-0.05 *$ & 0.03 & 0.04 & 0.05 & 0.15 ** & 0.06 \\
\hline Proportion of variation due to heterogeneity (I-square) & & 0.93 & & 0.64 & & 0.91 & & 0.96 \\
\hline \multicolumn{9}{|l|}{ Functional form } \\
\hline Dependent variable is not log transformed (ref) & $0.09 * *$ & 0.02 & $0.09 * *$ & 0.03 & & & & \\
\hline Dependent variable is log transformed & $-0.10 * *$ & 0.03 & -0.07 & 0.05 & & & & \\
\hline Proportion of variation due to heterogeneity (I-square) & & 0.88 & & 0.91 & & & & \\
\hline \multicolumn{9}{|l|}{ Mode assumption } \\
\hline $\begin{array}{l}\text { Assumes a stochastic frontier model (reference) } \\
\text { Assumes a purely deterministic model }\end{array}$ & & & & & & & $\begin{array}{r}-0.01 \\
0.12\end{array}$ & $\begin{array}{l}0.04 \\
0.06\end{array}$ \\
\hline Proportion of variation due to heterogeneity (I-square) & & & & & & & & 0.96 \\
\hline \multicolumn{9}{|l|}{ Covered region } \\
\hline National or other states (reference group) & $0.04 * *$ & 0.02 & $0.04 *$ & 0.02 & $0.06^{\star *}$ & 0.03 & 0.00 & 0.03 \\
\hline Virginia & $0.26 * *$ & 0.09 & $0.23 * *$ & 0.07 & 0.18 * & 0.10 & & \\
\hline California & -0.03 & 0.04 & $0.18 *$ & 0.09 & 0.00 & 0.05 & & \\
\hline Florida & $-0.07 *$ & 0.04 & 0.01 & 0.05 & -0.07 & 0.05 & 0.16 ** & 0.07 \\
\hline Proportion of variation due to heterogeneity (I-square) & & 0.93 & & 0.92 & & 0.93 & & 0.96 \\
\hline \multicolumn{9}{|l|}{ Data type } \\
\hline Use administrative data only (reference group) & 0.00 & 0.03 & $0.10^{* *}$ & 0.03 & 0.04 & 0.02 & 0.11 & 0.07 \\
\hline Use survey data only & $0.10 * *$ & 0.04 & & & 0.24 ** & 0.04 & -0.08 & 0.10 \\
\hline Use both administrative and survey data & 0.01 & 0.04 & $-0.08 *$ & 0.04 & -0.01 & 0.03 & -0.10 & 0.08 \\
\hline Proportion of variation due to heterogeneity (I-square) & & 0.86 & & 0.76 & & 0.50 & & 0.97 \\
\hline Number of observations & & 33 & & 13 & & 20 & & 18 \\
\hline
\end{tabular}

* $p<0.10$ ** $p<0.05$

Note:

1.Each panel represents a separate regression; a positive coefficient indicates that the given study feature predicts a higher level of the dependent variable for for-profits than not-for-profit hospitals. 
Table 4. Random-Effects Meta Regression: Comparison Between Not-For-Profit and Government Hospitals

\begin{tabular}{|c|c|c|c|c|c|c|}
\hline \multirow[b]{2}{*}{ Study Features } & \multicolumn{6}{|c|}{ Dependent Variable is the Standardized Effect Size } \\
\hline & \multicolumn{2}{|c|}{ Cost } & \multicolumn{2}{|c|}{ Profit Margin } & \multicolumn{2}{|c|}{ Efficiency } \\
\hline Methodology classification & Coef. & SE & Coef. & SE & Coef. & SE \\
\hline Type I (reference group) & -0.01 & 0.06 & 0.02 & 0.15 & -0.10 & 0.11 \\
\hline Type II & 0.06 & 0.06 & -0.03 & 0.12 & 0.10 & 0.10 \\
\hline Type III & 0.04 & 0.06 & 0.04 & 0.13 & 0.10 & 0.15 \\
\hline Ownership included as a control variable & $-0.05 *$ & 0.02 & -0.05 & 0.10 & 0.05 & 0.07 \\
\hline Proportion of variation due to heterogeneity (I-square) & & 0.76 & & 0.92 & & 0.95 \\
\hline \multicolumn{7}{|l|}{ Functional form } \\
\hline Dependent variable is not log transformed (ref) & 0.00 & 0.02 & 0.00 & 0.02 & & \\
\hline Dependent variable is log transformed & -0.01 & 0.02 & 0.02 & 0.02 & & \\
\hline Proportion of variation due to heterogeneity (I-square) & & 0.81 & & 0.02 & & \\
\hline \multicolumn{7}{|l|}{ Mode assumption } \\
\hline $\begin{array}{l}\text { Assumes a stochastic frontier model (reference) } \\
\text { Assumes a purely deterministic model }\end{array}$ & & & & & $\begin{array}{l}0.00 \\
0.04\end{array}$ & $\begin{array}{l}0.04 \\
0.06\end{array}$ \\
\hline Proportion of variation due to heterogeneity (I-square) & & & & & & 0.94 \\
\hline \multicolumn{7}{|l|}{ Covered region } \\
\hline National or other states (reference group) & 0.00 & 0.01 & -0.02 & 0.04 & -0.02 & 0.03 \\
\hline California & -0.05 & 0.05 & -0.02 & 0.08 & & \\
\hline Florida & 0.02 & 0.09 & & & $0.15 * *$ & 0.05 \\
\hline Proportion of variation due to heterogeneity (I-square) & & 0.80 & & 0.95 & & 0.90 \\
\hline \multicolumn{7}{|l|}{ Data type } \\
\hline Use administrative data only (reference group) & 0.07 & 0.04 & -0.02 & 0.07 & 0.11 * & 0.06 \\
\hline Use survey data only & -0.07 & 0.04 & -0.11 & 0.10 & $-0.14 *$ & 0.07 \\
\hline Use both administrative and survey data & -0.08 * & 0.04 & 0.02 & 0.08 & -0.09 & 0.07 \\
\hline Proportion of variation due to heterogeneity (I-square) & & 0.79 & & 0.88 & & 0.91 \\
\hline Number of observations & & 20 & & 7 & & 13 \\
\hline
\end{tabular}

* $p<0.10$ ** $p<0.05$

Note:

1.Each panel represents a separate regression; a positive coefficient indicates that the given study feature predicts a higher level of the dependent variable for government than not-for-profit hospitals. 
Appendix A1. Correlation Matrix of Study Features For Cost Studies

\begin{tabular}{|c|c|c|c|c|c|c|c|c|c|c|c|c|c|}
\hline \multirow[t]{2}{*}{ Studies comparing NFP and FP } & & & & & & & & & & & & & \\
\hline & 1 & 2 & 3 & 4 & 5 & 6 & 7 & 8 & 9 & 10 & 11 & 12 & 13 \\
\hline 1. Method type I & 1.00 & & & & & & & & & & & & \\
\hline 2. Method type II & -0.36 & 1.00 & & & & & & & & & & & \\
\hline 3. Method type III & -0.40 & -0.71 & 1.00 & & & & & & & & & & \\
\hline 4. Ownership as control & 0.15 & 0.34 & -0.45 & 1.00 & & & & & & & & & \\
\hline 5. Functional form is not log transformed & 0.56 & 0.06 & -0.48 & 0.11 & 1.00 & & & & & & & & \\
\hline 6. Functional form is log transformed & -0.56 & -0.06 & 0.48 & -0.11 & -1.00 & 1.00 & & & & & & & \\
\hline 7. National sample & -0.25 & -0.06 & 0.25 & 0.11 & -0.06 & 0.06 & 1.00 & & & & & & \\
\hline 8. California sample & 0.79 & -0.28 & -0.32 & 0.00 & 0.44 & -0.44 & -0.44 & 1.00 & & & & & \\
\hline 9. Virginia sample & -0.13 & 0.17 & -0.07 & 0.10 & 0.17 & -0.17 & -0.38 & -0.11 & 1.00 & & & & \\
\hline 10. Florida sample & -0.22 & 0.18 & -0.02 & -0.21 & -0.39 & 0.39 & -0.62 & -0.17 & -0.15 & 1.00 & & & \\
\hline 11. Administrative data only & 0.32 & 0.16 & -0.40 & 0.00 & -0.08 & 0.08 & -0.64 & 0.50 & -0.21 & 0.55 & 1.00 & & \\
\hline 12. Administrave and survey data & -0.40 & -0.25 & 0.55 & 0.00 & -0.48 & 0.48 & 0.25 & -0.32 & 0.34 & -0.30 & -0.63 & 1.00 & \\
\hline 13. Survey data only & 0.12 & 0.12 & -0.21 & 0.00 & 0.67 & -0.67 & 0.43 & -0.19 & -0.16 & -0.26 & -0.38 & -0.48 & 1.00 \\
\hline Studies comparing NFP and GOV & 1 & 2 & 3 & 4 & 5 & 6 & 7 & 8 & 9 & 10 & 11 & 12 & \\
\hline 1. Method type I & 1.00 & & & & & & & & & & & & \\
\hline 2. Method type II & -0.29 & 1.00 & & & & & & & & & & & \\
\hline 3. Method type III & -0.29 & -0.83 & 1.00 & & & & & & & & & & \\
\hline 4. Ownership as control & 0.15 & 0.43 & -0.52 & 1.00 & & & & & & & & & \\
\hline 5. Functional form is not log transformed & 0.42 & 0.07 & -0.31 & -0.13 & 1.00 & & & & & & & & \\
\hline 6. Functional form is log transformed & -0.35 & -0.27 & 0.47 & 0.04 & -0.83 & 1.00 & & & & & & & \\
\hline 7. National sample & 0.15 & -0.52 & 0.43 & -0.22 & -0.13 & 0.04 & 1.00 & & & & & & \\
\hline 8. Virginia sample & -0.10 & 0.35 & -0.29 & 0.15 & 0.42 & -0.35 & -0.67 & 1.00 & & & & & \\
\hline 9. Florida sample & -0.10 & 0.35 & -0.29 & 0.15 & -0.24 & 0.29 & -0.67 & -0.10 & 1.00 & & & & \\
\hline 10. Administrative data only & -0.15 & 0.52 & -0.43 & 0.22 & -0.36 & 0.43 & -0.39 & -0.15 & 0.67 & 1.00 & & & \\
\hline 11. Administrave and survey data & -0.24 & -0.31 & 0.45 & -0.13 & -0.18 & 0.31 & -0.13 & 0.42 & -0.24 & -0.36 & 1.00 & & \\
\hline 12. Survey data only & 0.35 & -0.10 & -0.10 & -0.04 & 0.45 & -0.63 & 0.43 & -0.29 & -0.29 & -0.43 & -0.69 & 1.00 & \\
\hline
\end{tabular}


Appendix A2. Correlation Matrix of Study Features For Revenue Studies

\begin{tabular}{|c|c|c|c|c|c|c|c|c|c|c|c|c|c|}
\hline \multicolumn{14}{|l|}{ Studies comparing NFP and FP } \\
\hline & 1 & 2 & 3 & 4 & 5 & 6 & 7 & 8 & 9 & 10 & 11 & 12 & 13 \\
\hline 1. Method type I & 1.00 & & & & & & & & & & & & \\
\hline 2. Method type II & -0.46 & 1.00 & & & & & & & & & & & \\
\hline 3. Method type III & -0.46 & -0.57 & 1.00 & & & & & & & & & & \\
\hline 4. Ownership as control & 0.26 & 0.07 & -0.31 & 1.00 & & & & & & & & & \\
\hline 5. Functional form is not log transformed & 0.24 & -0.52 & 0.30 & -0.23 & 1.00 & & & & & & & & \\
\hline 6. Functional form is log transformed & -0.38 & 0.39 & -0.04 & 0.26 & -0.42 & 1.00 & & & & & & & \\
\hline 7. Outcome is return to assets & 0.11 & 0.14 & -0.24 & -0.02 & -0.57 & -0.51 & 1.00 & & & & & & \\
\hline 8. National sample & -0.67 & 0.31 & 0.31 & 0.10 & -0.36 & 0.56 & -0.17 & 1.00 & & & & & \\
\hline 9. California sample & 0.77 & -0.36 & -0.36 & 0.04 & 0.44 & -0.29 & -0.15 & -0.52 & 1.00 & & & & \\
\hline 10. Virginia sample & 0.52 & -0.24 & -0.24 & 0.35 & -0.22 & -0.19 & 0.38 & -0.35 & -0.15 & 1.00 & & & \\
\hline 11. Florida sample & -0.29 & 0.13 & 0.13 & -0.43 & 0.18 & -0.29 & 0.09 & -0.52 & -0.22 & -0.15 & 1.00 & & \\
\hline 12. Administrative data only & 0.15 & 0.31 & -0.45 & -0.27 & 0.23 & -0.26 & 0.02 & -0.47 & 0.43 & -0.35 & 0.43 & 1.00 & \\
\hline 13. Administrave and survey data & -0.15 & -0.31 & 0.45 & 0.27 & -0.23 & 0.26 & -0.02 & 0.47 & -0.43 & 0.35 & -0.43 & -1.00 & 1.00 \\
\hline \multicolumn{14}{|l|}{ Studies comparing NFP and GOV } \\
\hline & 1 & 2 & 3 & 4 & 5 & 6 & 7 & 8 & 9 & & & & \\
\hline 1. Method type I & 1.00 & & & & & & & & & & & & \\
\hline 2. Method type II & -0.33 & 1.00 & & & & & & & & & & & \\
\hline 3. Method type III & -0.58 & -0.58 & 1.00 & & & & & & & & & & \\
\hline 4. Ownership as control & 0.33 & 0.33 & -0.58 & 1.00 & & & & & & & & & \\
\hline 5. Functional form is log transformed & -0.58 & 0.58 & 0.00 & -0.58 & 1.00 & & & & & & & & \\
\hline 6. Outcome is return to assets & 0.58 & -0.58 & 0.00 & 0.58 & -1.00 & 1.00 & & & & & & & \\
\hline 7. National sample & -1.00 & 0.33 & 0.58 & -0.33 & 0.58 & -0.58 & 1.00 & & & & & & \\
\hline 8. Virginia sample & 1.00 & -0.33 & -0.58 & 0.33 & -0.58 & 0.58 & -1.00 & 1.00 & & & & & \\
\hline 9. Administrative data only & -0.33 & 1.00 & -0.58 & 0.33 & 0.58 & -0.58 & 0.33 & -0.33 & 1.00 & & & & \\
\hline
\end{tabular}


Appendix A3. Correlation Matrix of Study Features For Profit Studies

\begin{tabular}{|c|c|c|c|c|c|c|c|c|c|c|c|}
\hline \multicolumn{12}{|l|}{ Studies comparing NFP and FP } \\
\hline & 1 & 2 & 3 & 4 & 5 & 6 & 7 & 8 & 9 & 10 & 11 \\
\hline 1. Method type I & 1.00 & & & & & & & & & & \\
\hline 2. Method type II & -0.45 & 1.00 & & & & & & & & & \\
\hline 3. Method type III & -0.39 & -0.65 & 1.00 & & & & & & & & \\
\hline 4. Ownership as control & 0.17 & 0.29 & -0.45 & 1.00 & & & & & & & \\
\hline 5. National sample & -0.52 & 0.29 & 0.15 & 0.14 & 1.00 & & & & & & \\
\hline 6. California sample & 0.78 & -0.35 & -0.30 & 0.00 & -0.41 & 1.00 & & & & & \\
\hline 7. Virginia sample & 0.21 & -0.03 & -0.15 & 0.28 & -0.47 & -0.19 & 1.00 & & & & \\
\hline 8. Florida sample & -0.24 & -0.03 & 0.24 & -0.47 & -0.47 & -0.19 & -0.22 & 1.00 & & & \\
\hline 9. Administrative data only & 0.34 & -0.04 & -0.24 & -0.15 & -0.45 & 0.55 & -0.35 & 0.43 & 1.00 & & \\
\hline 10. Administrave and survey data & -0.25 & -0.13 & 0.34 & 0.00 & 0.29 & -0.47 & 0.40 & -0.35 & -0.86 & 1.00 & \\
\hline 11. Survey data only & -0.14 & 0.32 & -0.21 & 0.28 & 0.28 & -0.11 & -0.13 & -0.13 & -0.21 & -0.32 & 1.00 \\
\hline
\end{tabular}

Note: Correlation matrix is omitted for studies comparing NFP and GOV hospitals, due to small sample size. 
Appendix A4. Correlation Matrix of Study Features For Efficiency Studies

\begin{tabular}{|c|c|c|c|c|c|c|c|c|c|c|c|}
\hline \multicolumn{12}{|l|}{ Studies comparing NFP and FP } \\
\hline & 1 & 2 & 3 & 4 & 5 & 6 & 7 & 8 & 9 & 10 & 11 \\
\hline 1. Method type I & 1.00 & & & & & & & & & & \\
\hline 2. Method type II & -0.60 & 1.00 & & & & & & & & & \\
\hline 3. Method type III & -0.27 & -0.60 & 1.00 & & & & & & & & \\
\hline 4. Ownership as control & -0.03 & 0.34 & -0.39 & 1.00 & & & & & & & \\
\hline 5. Functional form is SFR & -0.39 & 0.02 & 0.36 & 0.03 & 1.00 & & & & & & \\
\hline 6. Functional form is DEA & 0.39 & -0.02 & -0.36 & -0.03 & -1.00 & 1.00 & & & & & \\
\hline 7. National sample & -0.15 & -0.10 & 0.27 & -0.34 & 0.20 & -0.20 & 1.00 & & & & \\
\hline 8. Florida sample & 0.15 & 0.10 & -0.27 & 0.34 & -0.20 & 0.20 & -1.00 & 1.00 & & & \\
\hline 9. Administrative data only & 0.15 & -0.25 & 0.15 & -0.03 & -0.20 & 0.20 & -0.58 & 0.58 & 1.00 & & \\
\hline 10. Administrave and survey data & -0.17 & 0.29 & -0.17 & -0.15 & 0.38 & -0.38 & 0.17 & -0.17 & -0.52 & 1.00 & \\
\hline 11. Survey data only & 0.06 & -0.09 & 0.06 & 0.19 & -0.24 & 0.24 & 0.33 & -0.33 & -0.33 & -0.63 & 1.00 \\
\hline \multicolumn{12}{|l|}{ Studies comparing NFP and GOV } \\
\hline & 1 & 2 & 3 & 4 & 5 & 6 & 7 & 8 & 9 & 10 & 11 \\
\hline 1. Method type I & 1.00 & & & & & & & & & & \\
\hline 2. Method type II & -0.67 & 1.00 & & & & & & & & & \\
\hline 3. Method type III & -0.11 & -0.67 & 1.00 & & & & & & & & \\
\hline 4. Ownership as control & 0.33 & 0.00 & -0.33 & 1.00 & & & & & & & \\
\hline 5. Functional form is SFR & -0.37 & 0.05 & 0.30 & -0.10 & 1.00 & & & & & & \\
\hline 6. Functional form is DEA & 0.37 & -0.05 & -0.30 & 0.10 & -1.00 & 1.00 & & & & & \\
\hline 7. National sample & 0.17 & -0.25 & 0.17 & -0.50 & -0.20 & 0.20 & 1.00 & & & & \\
\hline 8. Florida sample & -0.17 & 0.25 & -0.17 & 0.50 & 0.20 & -0.20 & -1.00 & 1.00 & & & \\
\hline 9. Administrative data only & -0.17 & 0.25 & -0.17 & 0.00 & 0.20 & -0.20 & -0.38 & 0.38 & 1.00 & & \\
\hline 10. Administrave and survey data & -0.22 & 0.33 & -0.22 & -0.22 & 0.15 & -0.15 & -0.22 & 0.22 & -0.33 & 1.00 & \\
\hline 11. Survey data only & 0.33 & -0.50 & 0.33 & 0.20 & -0.30 & 0.30 & 0.50 & -0.50 & -0.50 & -0.65 & 1.00 \\
\hline
\end{tabular}

